\title{
Three-dimensional modeling of structural effects of corroding steel reinforcement in concrete
}

Kamyab Zandi Hanjari ${ }^{* a}$, Karin Lundgren ${ }^{\mathrm{a}}$, Mario Plos ${ }^{\mathrm{a}}$, Dario Coronelli ${ }^{\mathrm{b}}$

This is an Accepted Manuscript of an article published by Taylor \& Francis Group in Structure and Infrastructure Engineering, published online 24 Aug 2011, available online: http://dx.doi.org/10.1080/15732479.2011.607830

Full reference:

Zandi Hanjari, K., Lundgren, K., Plos, M. and Coronelli, D. (2013): Threedimensional modelling of structural effects of corroding steel reinforcement in concrete. Structure and Infrastructure Engineering 9 (7), pp.702-718. , http://dx.doi.org/10.1080/15732479.2011.607830 


\title{
Three-dimensional modeling of structural effects of corroding steel reinforcement in concrete
}

\author{
Kamyab Zandi Hanjari ${ }^{* a}$, Karin Lundgren ${ }^{\mathrm{a}}$, Mario Plos ${ }^{\mathrm{a}}$, Dario Coronelli ${ }^{\mathrm{b}}$ \\ ${ }^{a}$ Department of Civil and Environmental Engineering, Division of Structural \\ Engineering, Concrete Structures, Chalmers University of Technology, Sweden \\ ${ }^{b}$ Dipartimento di Ingegneria Strutturale, Politecnico di Milano, Italy \\ *Corresponding author's email: kamyab.zandi@chalmers.se
}

\begin{abstract}
The effect of corrosion products flowing through cracks becomes significant when large corrosion penetrations take place in reinforced concrete structures and wide cracks develop; this is favorable, as it decreases the splitting stress around the bar. The effect becomes more important when the corrosion rate is low, such as for natural corrosion. A corrosion model describing the expansion due to voluminous corrosive products was previously developed. The model is here extended to include the flow of corrosion products through cracks. The volume flow of corrosion products through a crack is assumed to depend on the splitting stress and the crack width. The splitting stress is evaluated from the strain in the corrosion products, and the crack width is computed from the displacements across the crack. A one-dimensional flow model is used to formulate the flow phenomenon and to estimate the volume flow of corrosion products. The extended corrosion model, applied in detailed three-dimensional non-linear finite element analyses of highly corroded eccentric pull-out specimens, resulted in more corrosion cracks with smaller crack openings, which better corresponded to measurements of the tested specimens. Moreover, the results indicated the important effect of the flow phenomenon on the bond strength.
\end{abstract}

Keywords: reinforced concrete, corrosion, reinforcement, modeling, FE analysis, corrosion products, bond

\section{Introduction}

Corrosion of steel reinforcement is one of the most common causes of deterioration in reinforced concrete structures. The corrosion process transforms steel reinforcement into corrosion products, leading to (a) a reduction of the cross sectional area and a change in the ductility of the reinforcement bars and (b) an expansion of volume that generates splitting stresses in the concrete. The latter effect may eventually crack and spall the surrounding concrete cover and adversely affect the bond between the reinforcement and concrete. These effects can be included in the analysis of corroding concrete components using different approaches. Structural analyses with beam or shell elements are the most common approaches in modeling reinforced concrete structures with a finite element method. In such models the interaction between reinforcement bars and surrounding concrete is usually simplified assuming full interaction, i.e. the strains in the reinforcements are computed from the displacement field of the adjacent concrete elements. This implies a perfect bond between the reinforcement and the surrounding concrete. Two-dimensional solid (continuum) elements are used in more detailed analyses of structural components. There, the interaction between the reinforcement and concrete can be modeled with a bond-slip relation. Both modeling approaches can take into account the primary effects of corrosion, i.e. the reduction of cross sectional area and the change in the ductility of the reinforcement bars. However, no direct account can be made of the volume 
expansion resulting from the corrosion products generating splitting stresses in the concrete.

Three-dimensional finite element modeling has been proved to be capable of comprehensively describing the behavior of reinforced concrete, provided that appropriate constitutive models are adopted. Furthermore, there can be a more realistic simulation of the effect of corrosion on the reinforcement, on the surrounding concrete, and on their interaction. Although detailed three-dimensional structural analyses are numerically expensive, they allow a detailed description of the corrosion damage at the material and structural levels.

Volume expansion of corrosion products that leads to cover cracking and spalling significantly influences the confinement conditions and consequently the steel/concrete bond. These effects have been taken into account in finite element models, e.g. by Lundgren (2005a and 2005b) and more recently by Richard et al. (2010) and Shodja et al. (2010). The bond model, by Lundgren (2005a), included the splitting stresses of the bond action, and the bond stress depended not only on the slip but also on the difference in radial deformation of the reinforcement bar and the concrete. This allowed a simulation of the loss of bond at splitting failure and at yielding of reinforcement. The bond model was combined with the corrosion model, Lundgren (2005b), in which the volume expansion of the corrosion products was simulated. The models used in three-dimensional modeling of corroded concrete specimens showed good agreement with test results for a relatively low corrosion attack, i.e. small corrosion penetration depth into the steel bar, (Lundgren 2005b). However, for larger corrosion attacks, the corrosion damage obtained in the analysis was considerably greater than that observed in the tests (Coronelli et al. 2010, Zandi Hanjari et al. 2010). The inconsistency observed between numerical analyses and tests for high corrosion attacks can be explained by the tendency of the corrosion products to penetrate into cracks and reach the external surface of the cover (Berra et al. 2003).

The flow of corrosion products through cracks and the consequent reduction of the splitting stresses around the bar is one of the main factors controlling crack propagation (Val et al. 2009). A comprehensive overview of the existing models for corrosion initiation and propagation with the focus on the phenomenon of corrosion products penetrating into concrete pores and flowing through cracks has been given in Val et al. (2009). Here, a critical review of the models published later, dealing with corrosion products flowing through cracks, is presented. The distribution of corrosion products on crack surfaces in reinforced ordinary Portland cement concrete (OPCC) and high performance concrete (HPC) subjected to different static and cyclic loadings has been examined by Jaffer and Hansson (2009). In their experiments, the concentrations of corrosion products at the bar interface and at the cracks were measured; no measurements of the flow rate of corrosion product through cracks were made. They observed that the opening and closing of cracks in salt solution under dynamic loading forced corrosion products away from the rebar/concrete interface and into the crack. Moreover, the results indicated that regardless of the type of loading, there was a larger distribution of corrosion products along the rebar surface in HPC than in OPCC. It was concluded that higher concentration of corrosion products along the rebar interface in HPC could act as a wedge and result in spalling of large pieces of concrete; there is less likelihood of such spalling in OPCC. Wong et al. (2010) studies the amount of corrosion products concentrated in the cement paste pores and the crack, and showed that once cracking has initiated, the corrosion 
products are preferentially deposited in the large cracks rather than pore spaces in the cement paste. However, the pressure required for penetration of corrosion products into cement pores and cracks was not studied. The model proposed by Shodja et al. (2010) accounts not only for the time evolution of normal stress buildup due to the development of corrosion, but also it incorporates the release of the normal pressure around the bar as some volume of the corrosion products flows though the cracks. Yet, the amount of corrosion products flowing through the cracks was assumed to be known in advance throughout the corrosion processes. Moreover, as no data were found on the amount of corrosion products flowing though cracks, this was estimated based on the best correspondence between the predicted and experimental data. Therefore, the amount of corrosion products flowing through cracks was left as an open problem (Shodja et al. 2010). In the current paper, a model is formulated for the flow of corrosion products through cracks and to estimate the volume flow of corrosion products.

In an earlier study by the authors, eccentric pull-out specimens were subjected to high corrosion attacks (Zandi Hanjari and Coronelli 2010). The study showed that, when the first corrosion crack occurred, corrosion products started to flow through cracks and reached the outer surface of the concrete. For high corrosion attacks, when several new cracks initiated and existing ones widened, the flow of corrosion products became significant. The flow of corrosion products not only depended on the number of cracks and the crack width but also varied in time. The flow of corrosion products continuously took place during the time in which the specimens were subjected to corrosion. This may significantly decrease the pressure around the corroded bars and may consequently reduce the damage to the surrounding concrete. Slow corrosion rates, i.e. corrosion penetration depth into the steel bar per unit of time, provide sufficient time for corrosion products to effectively flow through the cracks. This has been seen in real structures exposed to natural corrosive environments.

In this paper, a one-dimensional flow model described by a Lagrangian formulation was used to include the effect of flow of corrosion products through cracks. The model is based on a plug flow assumption, i.e. constant velocity of corrosion products across any cross section of the crack perpendicular to the axis of the crack. The previously developed corrosion model (Lundgren 2005b) was extended to include this phenomenon. The bond and corrosion models are first briefly described. A further development of the corrosion model to include the effect of corrosion products flowing through a crack is then described in detail. The response of the models is studied in a small portion, $120 \times 120 \times 10 \mathrm{~mm}^{3}$, of the eccentric pullout specimens. Finally, the extended model is applied in detailed three-dimensional non-linear analysis of the complete geometry of the eccentric pull-out specimens, and the results are discussed.

\section{Previously developed bond and corrosion models}

In earlier work (Lundgren and Gylltoft 2000), a general model of the bond mechanism was developed; the model was later combined with the modeling of corrosion attack of reinforcement (Lundgren 2002). The modeling approach is especially suited for detailed three-dimensional finite element analyses, where both the concrete and the reinforcement are modeled with solid elements. Surface interface elements are used at the steel/concrete interaction to describe a relation between the stress, $\sigma$, and the relative displacement, $u$, in the interface. The physical interpretations of variables $\sigma_{n}$, $\sigma_{t}, u_{n}$ and $u_{t}$ are shown in Figure 1. The corrosion model and bond model can be 
viewed as two separate layers around a reinforcement bar. Due to equilibrium between the two layers, the stress, $\sigma$, is the same in the bond and in the corrosion layers. The deformations are related as:

$$
\begin{aligned}
& u_{n}=u_{n c o r}+u_{n b o n d} \\
& u_{t}=u_{n b o n d}, \quad u_{t c o r}=0
\end{aligned}
$$

where index cor means the corrosion layer and index bond means the bond layer. Equations (1) and (2) are solved in the interface element together with the condition for equilibrium using an iterative procedure.

\subsection{Bond model}

The bond model, first formulated in Lundgren and Gylltoft (2000) and later modified in Lundgren (2005a), is a frictional model that uses elasto-plastic theory to describe the relations between stresses and deformations. The relation between the stresses, $\sigma$, and the relative displacements, $u$, is in the elastic range:

$$
\left[\begin{array}{c}
\sigma_{n} \\
\sigma_{t} \\
\sigma_{r}
\end{array}\right]=\left[\begin{array}{ccc}
D_{11} & 0 & 0 \\
0 & D_{22} & 0 \\
0 & 0 & D_{33}
\end{array}\right]\left[\begin{array}{l}
u_{n} \\
u_{t} \\
u_{r}
\end{array}\right]
$$

where $D_{11}$ and $D_{22}$ describe the relation between displacements and stresses in the radial and longitudinal directions of the bar, respectively. The third component, added for three-dimensional modeling, corresponds to the stress acting in the tangential direction, around the bar. This component was assumed to be independent of the other components; $D_{33}$ is a dummy stiffness preventing the bar from rotation around its axis.

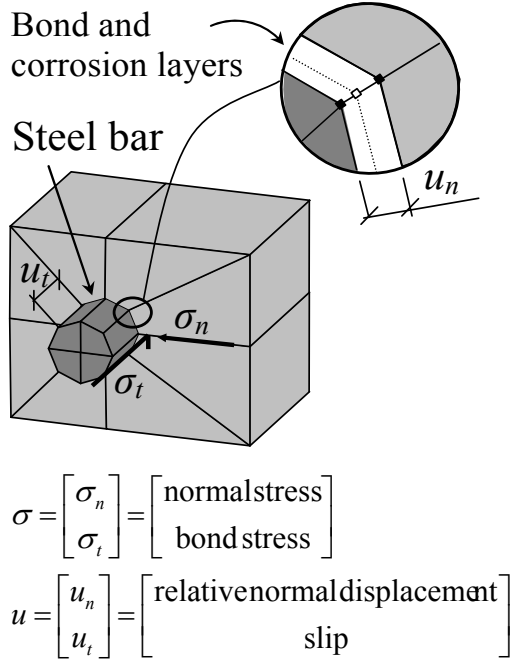

(a)

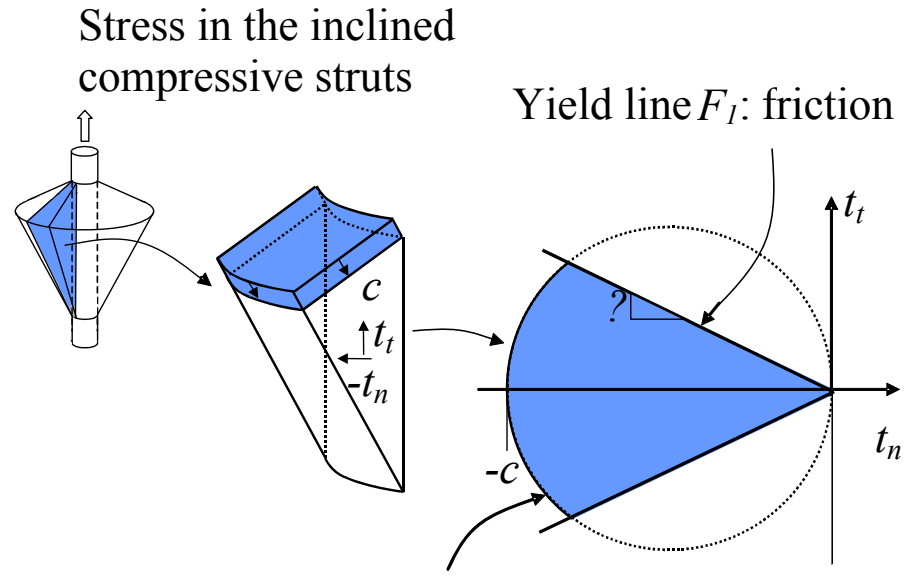

Yield line $F_{2}$ : the upper limit at a pullout failure

(b)

Figure 1. (a) Physical interpretation of variables $\sigma_{n}, \sigma_{t}, u_{n}$ and $u_{t}$, and (b) yield surface of the model, both modified from Lundgren (2005a). 
The yield lines of the model are described by two yield functions: one explains the friction, $F_{1}$, assuming that the adhesion is negligible, and the other, $F_{2}$, describes the upper limit for a pull-out failure determined from the stress in the inclined compressive struts that result from the bond action:

$$
\begin{aligned}
& F_{1}=\left|\sigma_{t}\right|+\mu \sigma_{n}=0 ; \\
& F_{2}=\sigma_{t}^{2}+\sigma_{n}^{2}+c \cdot \sigma_{n}=0
\end{aligned}
$$

More details on yield lines, flow rules and hardening laws is given in Lundgren (2005a). The model was used in simulations of several pull-out tests and beam tests with anchorage failure (Lundgren and Magnusson 2001) and gave results in good agreement with the experiments.

\subsection{Corrosion model}

The corrosion model was developed in Lundgren (2002) and further calibrated with several tests in Lundgren (2005b). The effect of corrosion has been modeled as the volume increase of the corrosion products compared to the virgin steel. The volume of the corrosion products relative to the uncorroded steel, $v_{r s}$, and the corrosion penetration depth into the steel bar as a function of the time, $x$, were used to calculate the free increase of the bar radius, i.e. the increase in radius including the corrosion products when the normal stresses were assumed to be zero. The corrosion process was then modeled by taking time steps. The physical interpretation of the variables in the corrosion model is shown in Figure 2. The free increase of the radius was calculated from geometry as:

$$
y=-r+\sqrt{r^{2}+\left(v_{r s}-1\right) \cdot\left(2 r x-x^{2}\right)}
$$

where $r$ is the original bar radius. The real increase of the radius, $u_{n c o r}$, is smaller owing to the confinement from the surrounding concrete. This results in a total strain in the corrosion products, $\varepsilon_{c o r}$, of:

$$
\varepsilon_{c o r}=\frac{u_{n c o r}-y}{x+y}
$$

Corresponding stresses normal to the bar surface were determined from the normal strain in the corrosion products. The mechanical behavior of the corrosion products at loading was described as:

$$
\sigma_{n}=K_{c o r} \cdot \varepsilon_{c o r}^{p}
$$

where $K_{c o r}$ represents the stiffness of the corrosion products in the radial direction, $\varepsilon_{c o r}$ is the strain in the corrosion products and $p$ is an exponent that describes the granular behavior. It should be noted that the reduction of bar cross sectional area due to corrosion is not considered in the corrosion model. This should be done by adapting the yield and ultimate strengths as well as Young's modulus of the steel bar accordingly. 


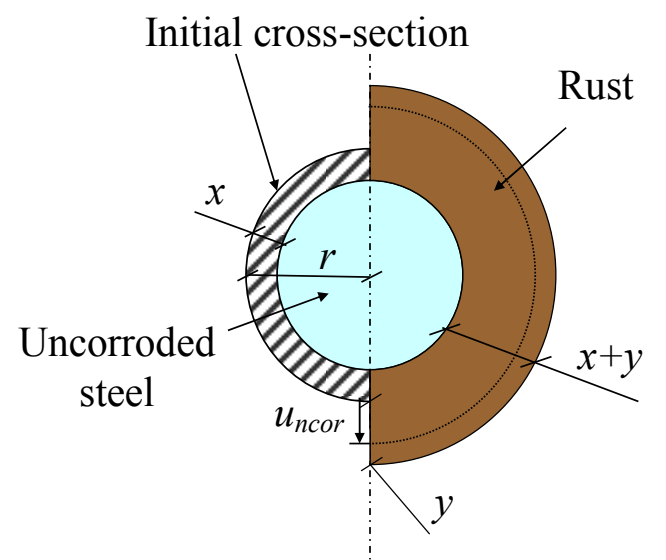

Corrosion penetration: $x$

Volume rust / volume steel: $v_{r s}$

Free increase of the radius: $y$

Real increase of the radius: $u_{n c o r}$

Figure 2. Physical interpretations of the variables in the corrosion model, modified from (Lundgren 2005b).

\section{Development of the corrosion model}

The corrosion model was extended to include the effect of corrosion products flowing through cracks. The volume of corrosion products that flowed through a crack, $V$, was assumed to depend on (a) the normal stress in the corrosion products and (b) the crack width. The normal stress in the corrosion products, as in the earlier version of the corrosion model, was evaluated from the strain in the corrosion products according to equation (8). The crack width closest to the bar, $w_{c r}$, was computed from the nodal displacements across the crack, see Figure 3. It was assumed that the crack had a constant width of $w_{c r}$ along its depth. As the crack width increases near the concrete surface, the assumption of constant crack width along its depth leads to a slight underestimation of the flow of corrosion products through cracks, which gives a larger safely margin on the model. The cross sectional area of the crack through which corrosion products flows was calculated as:

$$
A_{c r}=w_{c r} \cdot e
$$

where $A_{c r}$ is the section area of the crack, $w_{c r}$ is the crack width and $e$ is the element size along the crack.

The corrosion time, i.e. duration of the corrosion process, and corrosion rate, i.e. corrosion penetration depth into the steel bar per unit of time, were also given as input to the model. The corrosion penetration depth into the steel bar, $x$, was determined theoretically based on Faraday's law according to:

$$
x=11.6 \cdot(t \cdot I)
$$

where $x$ is the corrosion penetration depth into the steel bar in $\mu \mathrm{m} ; t$ is the corrosion time in year; and $I$ is the impressed current density in $\mu \mathrm{A} / \mathrm{cm}^{2}$. If the volume flow of corrosion products, $V$, is known, the free increase of radius of the corroded bar can be given from geometry as:

$$
y_{e x t}=-r+\sqrt{r^{2}+\left(v_{r s}-1\right)\left(2 r x-x^{2}\right)-\frac{V}{\pi \cdot e}}
$$




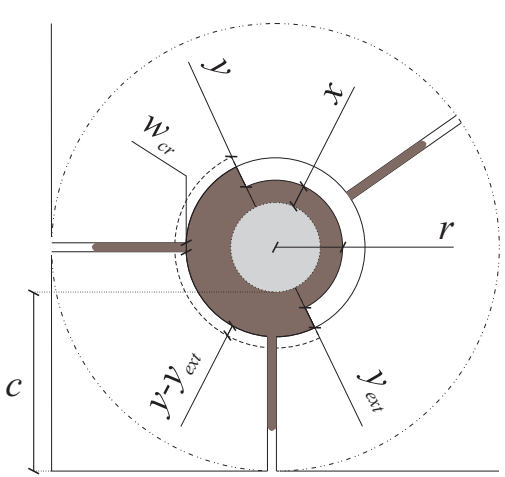

(a)

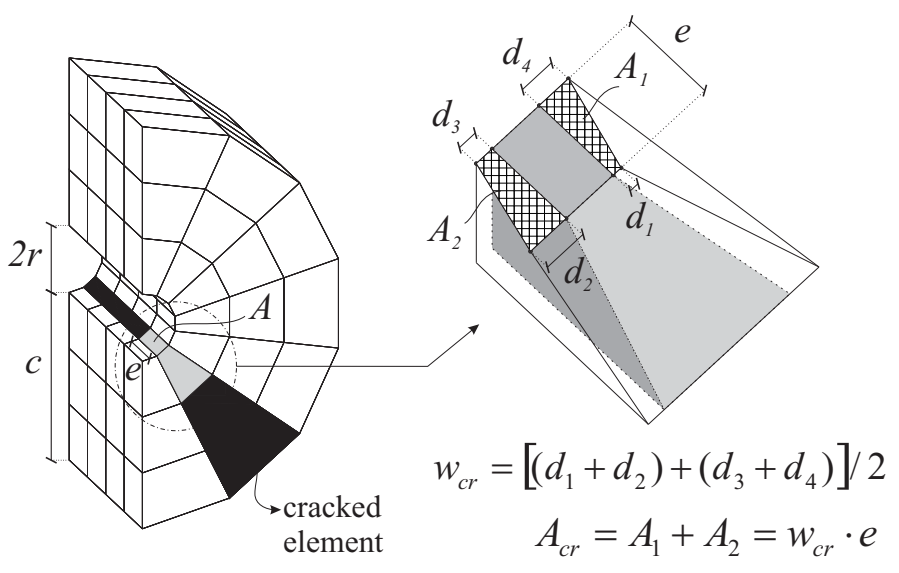

(b) (c)

Figure 3. (a) Physical interpretations of the variables in the extended corrosion model, (b) section area of the crack through which rust flows and (c) crack width computed from the nodal displacements.

where $y_{\text {ext }}$ is the free increase of the radius due to the remaining corrosion products around the corroded bar, $r$ is the original bar radius and $v_{r s}$ is the volume of the corrosion products relative to the uncorroded steel. The total strain in the corrosion products, $\varepsilon_{c o r}$, is then calculated in a way similar to that in the original model using equation (7). The deformation in the interface layer, divided between the bond layer and the corrosion layer, was computed using an iterative procedure. The formulation of the one-dimensional corrosion products flow, the calculation of the volume flow of corrosion products and the corresponding assumptions are described in the following.

\subsection{Formulation of one-dimensional flow of corrosion products}

A one-dimensional flow based on a plug flow model, i.e. constant velocity of the corrosion products flow along a crack, was applied to describe the phenomenon, see Figure 4. The motion of the corrosion products is described with the Lagrangian formulation, which is typically used in solid particle and rigid body mechanics. The Lagrangian description provides the position of the corrosion products particles within time. The phenomenon was expressed as an ideal flow, i.e. the friction in the crack was assumed to be negligible. The profile of the corrosion products velocity across the crack was assumed to be constant. The velocity, $v$, and acceleration, $a$, of a corrosion products particle during a time span $\Delta t$ was determined as in the kinematics of rigid bodies, where $x=x(t)$ represents the position of a corrosion products particle with time. Thus,

$$
\begin{aligned}
& v=v(t)=\frac{\Delta x(t)}{\Delta t} \\
& a=a(t)=\frac{\Delta v(t)}{\Delta t}=\frac{\Delta^{2} x(t)}{\Delta t^{2}}
\end{aligned}
$$


In classical mechanics, a motion is described by the second law of Newton. Hence, the acceleration, $a$, of a particle with a mass of $m$ subjected to external force $\sum F$ is given by

$$
\sum F=m a
$$

The motion of corrosion products particles is driven by the normal stress in the corrosion products, $\sigma_{n}$, and thus the external force acting on the section area of the crack, see Figure 4, is calculated as

$$
\sum F=A_{c r} \cdot \sigma_{n}
$$

The change in the velocity of corrosion products particles, $\Delta v$, according to equations (13-15), can be expressed as

$$
\Delta v=\frac{A_{c r} \cdot \sigma_{n}}{m} \cdot \Delta t
$$

The amount of corrosion products transported across the section area of crack, $A_{c r}$, per time span of $\Delta t$ is given by the mass flow rate (flux),

$$
\frac{\Delta m}{\Delta t}=\rho \cdot \bar{v} \cdot A_{c r}
$$

where $\rho$ is the density of corrosion products and $\bar{v}$ is the mean velocity of corrosion products particles during time span $\Delta t$. The volume flow of corrosion products, $\Delta V$, during time span $\Delta t$ through the section area of the crack, $A_{c r}$, can therefore be expressed by

$$
\Delta V=\frac{\Delta m}{\rho}=\bar{v} \cdot A_{c r} \cdot \Delta t
$$

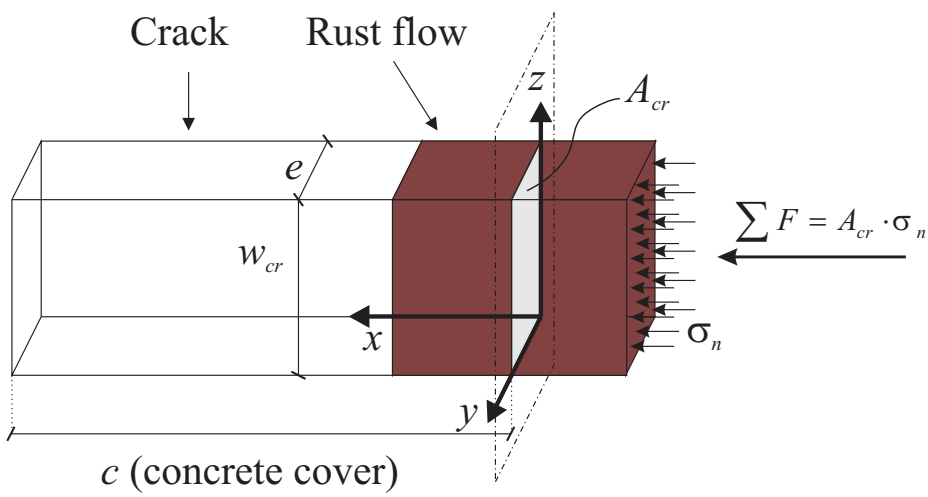

Figure 4. One-dimensional rust flow. 


\subsection{Volume flow of corrosion products in time steps}

The total volume flow of corrosion products, $V$, through a crack is calculated as the summation of the volume flow of corrosion products in time steps (increments), $\Delta V_{i}$, as

$$
V=\sum_{i=1}^{j} \Delta V_{i}
$$

where index $i$ is the time increment number. The change in the velocity of corrosion products particles in time step $i$ according to Equation (16) is expressed as

$$
\Delta v_{i}=\frac{A_{c r, i-1} \cdot \sigma_{n, i-1}}{m_{i}} \cdot \Delta t_{i}
$$

It is assumed that the velocity of corrosion products particles crossing the section area changes linearly during time step $m$; therefore,

$$
\bar{v}_{i}=v_{i-1}+\frac{1}{2} \Delta v_{i}=v_{i-1}+\frac{1}{2}\left(\frac{A_{c r, i-1} \cdot \sigma_{n, i-1}}{m_{i}} \cdot \Delta t_{i}\right)
$$

According to equation (18), the volume flow of corrosion products in time step $i$ is expressed as

$$
\Delta V_{i}=\bar{v}_{i} \cdot A_{c r, i-1} \cdot \Delta t_{i}
$$

Thus, according to equations (21) and (22),

$$
\Delta V_{i}=\left[v_{i-1}+\frac{1}{2}\left(\frac{A_{c r, i-1} \cdot \sigma_{n, i-1}}{m_{i}} \cdot \Delta t_{i}\right)\right] \cdot A_{c r, i-1} \cdot \Delta t_{i}
$$

The total mass of corrosion products flowing through a crack is calculated as the summation of the mass flow of corrosion products in time steps by

$$
m=\sum_{i=1}^{j} \Delta m_{i}
$$

Thus,

$$
m_{i}=m_{i-1}+\Delta m_{i}=\rho\left(V_{i-1}+\Delta V_{i}\right)
$$

Finally, the volume flow of corrosion products in one time step is calculated as

$$
\Delta V_{i}=\left[v_{i-1}+\frac{1}{2}\left(\frac{A_{c r, i-1} \cdot \sigma_{n, i-1}}{\rho\left(V_{i-1}+\Delta V_{i}\right)} \cdot \Delta t_{i}\right)\right] \cdot A_{c r, i-1} \cdot \Delta t_{i}
$$




\subsection{Assumptions}

The following assumptions were made:

(1) The strain localizes in the concrete element closest to the bar when the tensile stress reaches the tensile strength of concrete. It was therefore assumed that the first crack took place in the analysis when the strain in the concrete element closest to the bar became greater than $f_{t} / E_{c}$, thus

$$
\begin{array}{llrl}
w_{c r}=0 & \text { if } & \varepsilon<\frac{f_{t}}{E_{c}} \\
w_{c r}=\frac{\left(d_{1}+d_{2}\right)+\left(d_{3}+d_{4}\right)}{2} & \text { if } & \varepsilon \geq \frac{f_{t}}{E_{c}}
\end{array}
$$

where $\varepsilon$ is the strain in the concrete element closest to the bar, $f_{t}$ is the tensile strength of concrete, $E_{c}$ is the elastic modulus of concrete, and $d_{1}-d_{4}$ are the nodal displacements, see Figure 3. Equation (28) also means that the entire tensile deformation in the concrete is considered as crack width after the crack is initiated.

(2) The depth of the crack, $c$, through which corrosion products flow, was assumed to be equal to the concrete cover in all directions around the bar, see Figure 3. Thus the volume inside the crack, $V_{c}$, which can be occupied with corrosion products is calculated as

$V_{c}=e \cdot w_{c r} \cdot c$

where $e$ is the element size and $c$ is the concrete cover. Before the crack is filled with corrosion products, the normal stress acts on the volume of the corrosion products that is inside the crack, $V_{i-1}+\Delta V_{i}$. When the crack is completely filled with corrosion products, the total volume of corrosion products becomes $V_{c}$ and, therefore, equation (26) is expressed as

$$
\begin{aligned}
& \Delta V_{i}=\left[v_{i-1}+\frac{1}{2}\left(\frac{A_{c r, i-1} \cdot \sigma_{n, i-1}}{\rho\left(V_{i-1}+\Delta V_{i}\right)} \cdot \Delta t_{i}\right)\right] \cdot A_{c r, i-1} \cdot \Delta t_{i} \quad \text { if } \quad V_{i-1}<V_{c} \\
& \Delta V_{i}=\left[v_{i-1}+\frac{1}{2}\left(\frac{A_{c r, i-1} \cdot \sigma_{n, i-1}}{\rho\left(V_{c}\right)} \cdot \Delta t_{i}\right)\right] \cdot A_{c r, i-1} \cdot \Delta t_{i} \quad \text { if } V_{i-1} \geq V_{c}
\end{aligned}
$$

(3) The total volume flow of corrosion products, $V$, can never be greater than the volume of the corrosion products, $V_{\text {rust }}$. Thus,

$V<V_{\text {rust }}$

where $V_{r u s t}=A \cdot x \cdot v_{r s}$ and $A$ is the area of the element, see Figure 3(b). 
(4) Due to numerical instability caused by negative volume flow, it was assumed that the volume of corrosion products flowing through a crack in each time step cannot flow back to the corrosion products layer surrounding the reinforcement bar. This is expressed as

$$
\Delta V_{i} \geq 0
$$

\subsection{Discussion of the model}

The most important feature of the model is that the volume flow of corrosion products depends on both the crack width and the pressure around the bar. The original and the extended corrosion models are expected to give the same results before the first corrosion crack occurs; this is defined by assumption (1). The first crack exhibits a small opening in the early stage, which allows for a small volume of corrosion products to flow through the crack. Moreover, the cracking leads to a sudden reduction in the pressure around the bar. A relatively small influence of corrosion products flow is therefore expected shortly after the first cracking. A larger volume of corrosion products flows through the cracks at higher corrosion attacks when wide cracks propagate; this is likely to significantly influence the crack width and the pressure around the bar. The reduction in the crack width is also expected to delay numerical instability in the finite element analysis. The analysis can thus be carried out for higher corrosion attacks.

It should be noted that the volume flow of corrosion products also depends on the corrosion rate. A high corrosion rate significantly shortens the time to reach a particular corrosion penetration depth; a smaller volume of corrosion products thereby flows through the crack, see equation (26). The model is thus expected to give different results for varying corrosion rates; larger differences in the results from the original and the extended corrosion models are expected when a low corrosion rate is adopted.

Another important difference between the original and the extended model is the development of the normal stresses around the bar for a high corrosion attack. These are much larger when the original corrosion model is used. When the extended model is used, the normal stress associated with the cracked element reduces, while the normal stress associated with other elements around the bar maintains. This gives the possibility for other cracks around the bar to initiate and propagate. Therefore, a greater number of cracks with smaller crack widths are expected. Moreover, in the original corrosion model, the free increase of the radius depends only on the corrosion penetration depth into the steel bar and on the volume expansion of corrosion products. The free increase of radius is thus the same for a given corrosion attack in all the elements, while the free increase of radius also depends on the volume of corrosion products flow in the extended corrosion model, see equation (11). Thereby, for a given corrosion attack, a varying free increase of radius is obtained in different interface elements around the reinforcement bar. This means a non-uniform free increase of radius around and along the corroded bar. The correspondence of such a phenomenon with what occurs around the bar in real corrosion needs to be further studied.

Moreover, in chloride-induced corrosion, where cracks are initiated by small localized pits of corrosion, the assumption of one-dimensional flow of corrosion products through cracks may no longer be applicable. In this case, a two-dimensional flow of corrosion products through crack planes may correspond better to the actual 
phenomenon. It should also be noticed that, as a consequence of assumption (1), the extended corrosion model accounts for the flow of corrosion products only through the cracks which are parallel to the corroding bar, and only along a crack length equal to the length of the corroding bar. One way to resolve this is to move from a local corrosion model to a non-local one. However, a non-local approach would extensively add to the complexity of the model and was therefore not adopted in this article.

\subsection{Evaluation of the model}

The original and extended corrosion models were used in analyses of a small portion of eccentric pull-out specimens, see Figure 5. The geometry studied had a dimension of $120 \times 120 \times 10 \mathrm{~mm}^{3}$ and included one eccentric bar of $20 \mathrm{~mm}$ in diameter. The concrete and reinforcement were modeled with three-dimensional solid elements of $10 \mathrm{~mm}$. The crack band width was assumed to be equal to the element size; this was later verified to be a good approximation of the localization zone in the analyses. The models suggested by Thorenfeldt et al. (1991) and Hordijk (1987) were adopted for the concrete in compression and tension, respectively. Three different corrosion rates, resulted from 1,100 and $500 \mu \mathrm{A} / \mathrm{cm}^{2}$ impressed current density, were chosen in the analysis with the extended corrosion model. The corrosion rates measured in normal climate conditions has been lower than $10 \mu \mathrm{A} / \mathrm{cm}^{2}$ (Shodja et al. 2010, Alonso et al. 1998). The corrosion rate of $1 \mu \mathrm{A} / \mathrm{cm}^{2}$ was chosen so that it falls within the range of the corrosion rate may be measured in a natural aggressive environment. Spurious bond deterioration has been reported for specimens subjected to impressed current densities of higher than $250 \mu \mathrm{A} / \mathrm{cm}^{2}$ (Saifullah and Clark 1994). Therefore, the other two corrosion rates, 100 and $500 \mu \mathrm{A} / \mathrm{cm}^{2}$, were chosen so that they represent the corrosion rates well below and above the threshold corrosion rate. These choices allow a better evaluation of the response of the extended corrosion model.

The compressive strength of concrete was equal to $27.7 \mathrm{MPa}$ and the tensile strength was 2.2 MPa. Other material properties of concrete, such as the elastic modulus and fracture energy, were calculated on the basis of Eurocode 2. The reinforcement bar had a yield and ultimate strength of $510 \mathrm{MPa}$ and $610 \mathrm{MPa}$, respectively, and an elastic modulus of $200 \mathrm{GPa}$. The input data for the bond and the original corrosion models were given in Lundgren $(2005 \mathrm{a}, 2005 \mathrm{~b})$. The additional input data for the extended corrosion model are the density of corrosion products, $\rho$, assumed to be $4049 \mathrm{~kg} / \mathrm{m}^{3}$ (Ouglova et al. 2006), and the concrete cover, $c$, which was equal to 30 $\mathrm{mm}$ in the geometry studied, see Figure 5.

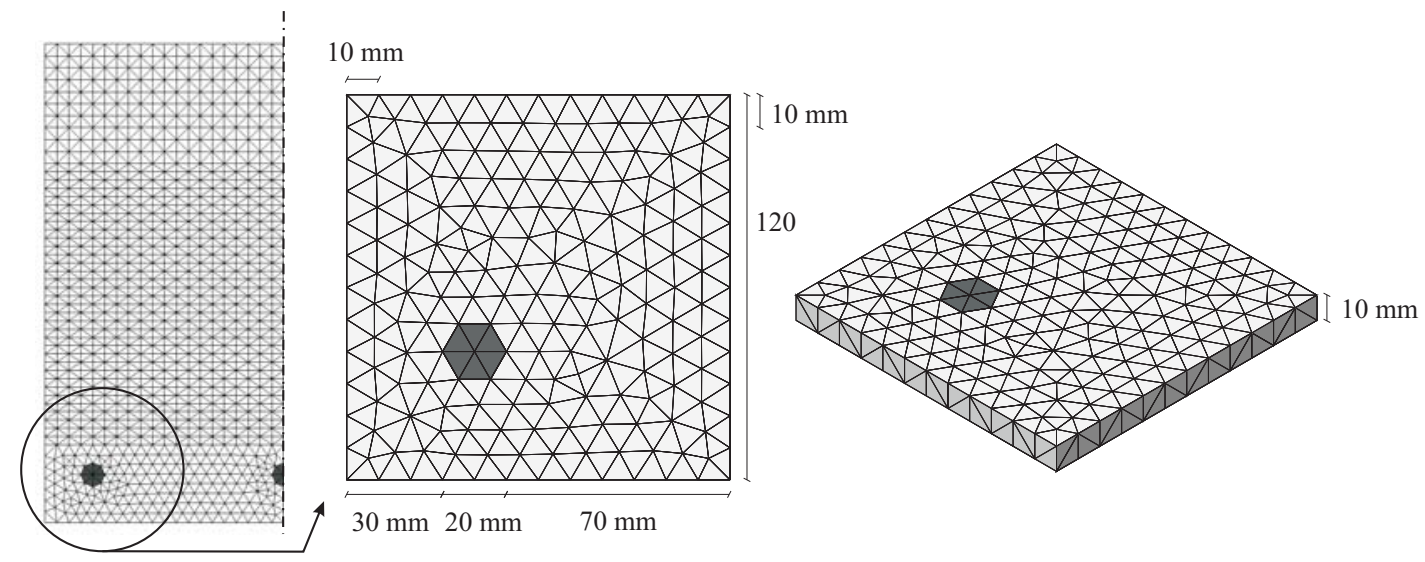

Figure 5. Geometry and FE model of a small part of the eccentric pull-out specimens. 
The volume of the corrosion products relative to the uncorroded steel, $v_{r s}$, for some typical oxides given in the literature (Liu and Weyers 1998) varies between 1.7 for $\mathrm{FeO}$ and 6.15 for $\mathrm{Fe}(\mathrm{OH})_{3} 3 \mathrm{H}_{2} \mathrm{O}$. The value of 2.0 (Molina et al. 1993) is frequently used in numerical analysis of corroding reinforcement steel in concrete (Lundgren 2003, Coronelli and Gambarova 2004, Lundgren et al. 2007, Zandi Hanjari 2008). The same value was chosen here in the analyses with the original and the extended corrosion models.

The analysis using the original model could only be carried out to a corrosion attack equivalent to a rebar weight loss of $2.6 \%$. This corrosion attack corresponded to extensive cover cracking. Severe damage of the concrete resulted in numerical instability in the analysis for any higher corrosion attack. However, the analyses using the extended model could be continued with higher corrosion attacks. In these analyses, numerical instability did not occur until there were corrosion attacks equivalent to rebar weight losses of $7.5 \%, 5.6 \%$ and $4.7 \%$, when the impressed current densities were 1,100 and $500 \mu \mathrm{A} / \mathrm{cm}^{2}$, respectively. This indicates that, when wide cracks developed for low corrosion rates, the favorable effect of corrosion products flowing through cracks became significant and considerably decreased the splitting stress and consequently the damage to the surrounding concrete.

The results of the two models in terms of the free increase in corrosion products versus rebar weight loss are compared in Figure 6 (a). It can be noted that the same results are obtained in the original model regardless of the corrosion rate; i.e. a given corrosion attack caused the same free increase regardless of the time. On the other hand, the corrosion rate did influence the results in the extended model. The two models gave similar results before the initiation of the first crack, which took place at about $1.0 \%$ rebar weight loss. For higher corrosion attacks, the free increase in corrosion products in the analyses with the extended model was smaller than that in the original model. The difference in the free increase of corrosion products increased rapidly for higher corrosion attacks. This was expected, as the volume flow of corrosion products depended on both time and corrosion penetration depth into the steel bar. Comparison of the crack width, Figure 6 (b), and crack pattern, Figure 7, shows that the extended model resulted in more corrosion cracks with smaller crack openings. It was also found that the results were considerably influenced by the corrosion rate. In the analysis with a low corrosion rate, resulted from $1 \mu \mathrm{A} / \mathrm{cm}^{2}$ impressed current density, the crack width became sufficiently large so that all the corrosion products produced after about 3\% rebar weight loss flowed through the cracks and did not lead to a further increase of splitting stress around the bar.

Figure 6 (b) suggests that the rate of crack width development is directly related to the corrosion rate, i.e. the cracks may grow faster in width as the corrosion rate increases. The experimental evidences found in the literature support this only for corrosion rates higher than $200 \mu \mathrm{A} / \mathrm{cm}^{2}$, (Saifullah and Clark 1994, Alonso et al. 1998, Vu et al. 2005); while, for corrosion rates lower than $200 \mu \mathrm{A} / \mathrm{cm}^{2}$, experimental results indicate the opposite, i.e. cracks tend to grow faster in width as the corrosion rate decreases (Alonso et al. 1998, Mullard and Stewart 2010). However, the literature provides no verified explanation to such a phenomenon; therefore, this was not included in the current version of the extended corrosion model. This problem requires further investigation. 


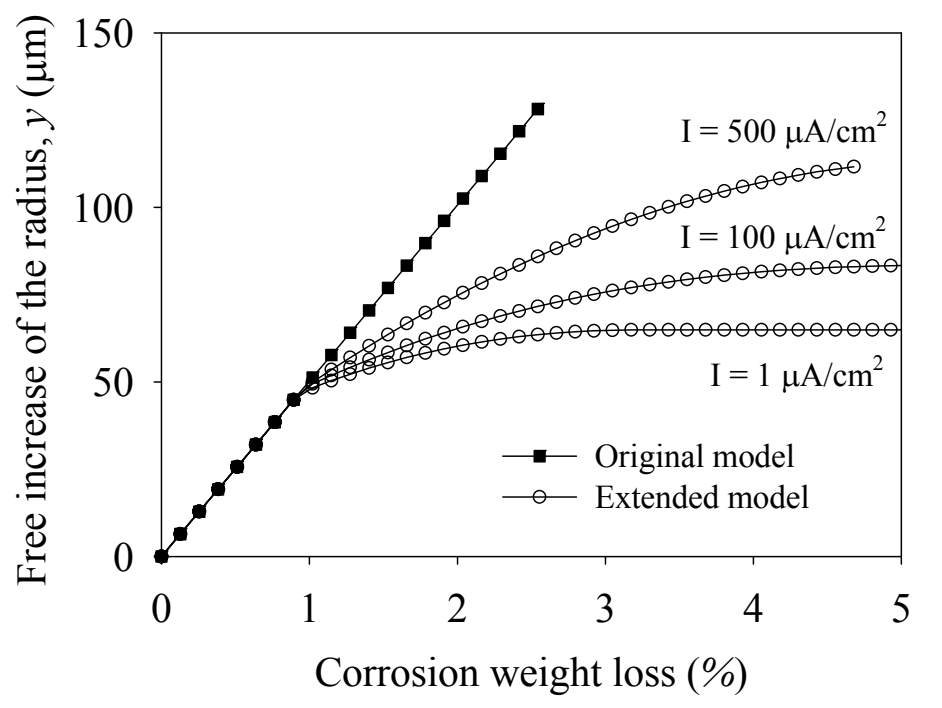

(a)

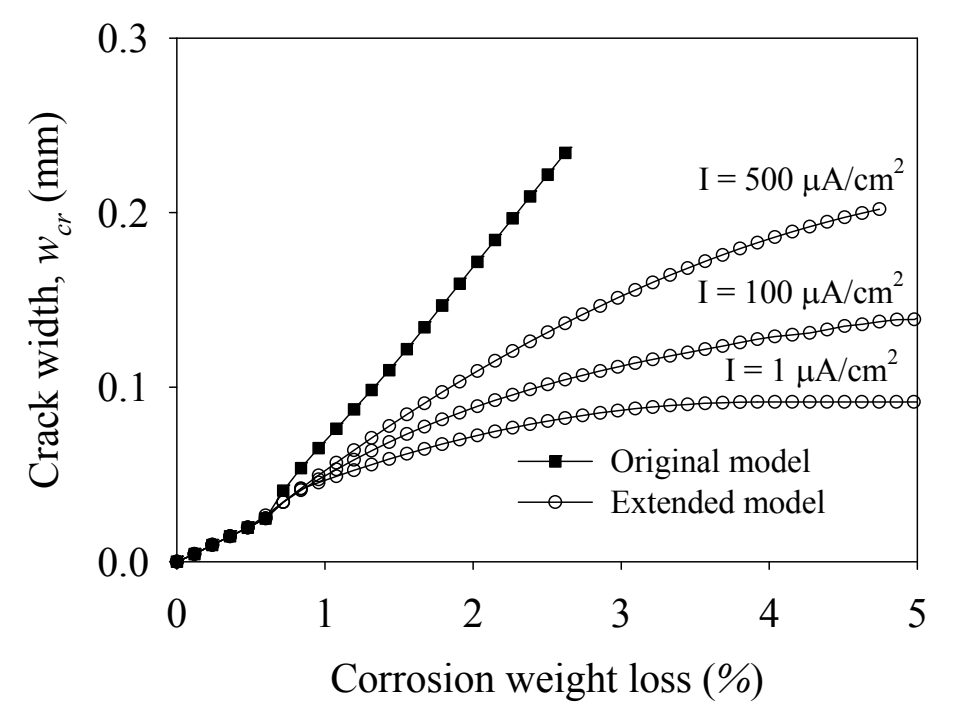

(b)

Figure 6. Numerical results in terms of (a) free increase of the radius and (b) crack width versus corrosion weight loss.

The effect of corrosion products flow may also partially explain the spurious deterioration observed in specimens subjected to a high corrosion rate (Saifullah and Clark 1994, Yuan et al. 2007). The time needed to reach a corrosion attack is considerably shortened with a high corrosion rate; thus, the flow of corrosion products through cracks does not take place in an effective way. This is an important phenomenon that may significantly affect experiments and numerical analyses dealing with high corrosion attacks. 


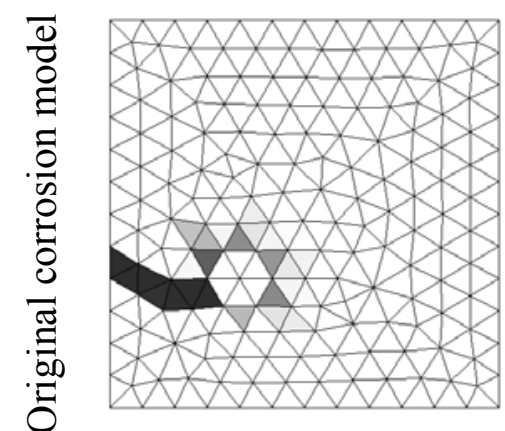

weight loss $1.0 \%$

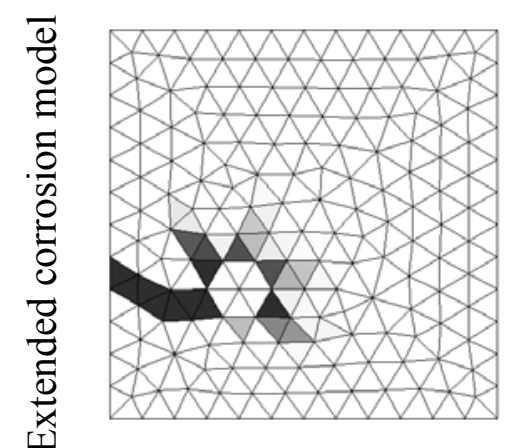

weight loss $1.0 \%$

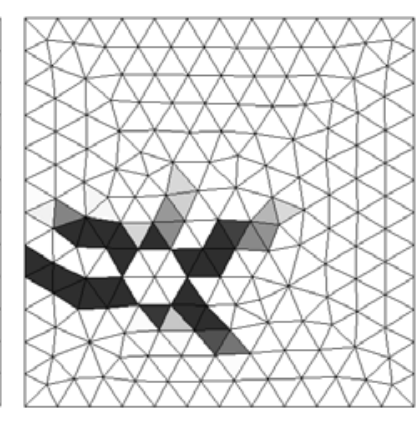

weight loss $1.6 \%$

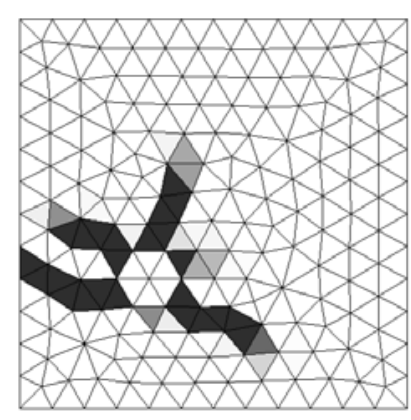

weight loss $1.6 \%$

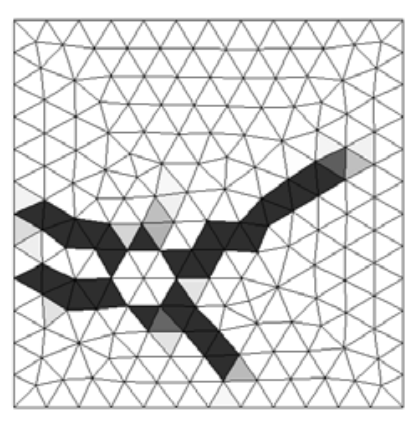

0

$0.1 \mathrm{E}-3$

$0.2 \mathrm{E}-3$

$0.3 \mathrm{E}-3$

$0.4 \mathrm{E}-3$

$0.5 \mathrm{E}-3$

$0.6 \mathrm{E}-3$

$0.7 \mathrm{E}-3$

$0.8 \mathrm{E}-3$

$0.9 \mathrm{E}-3$

$0.1 \mathrm{E}-2$ weight loss $2.6 \%$

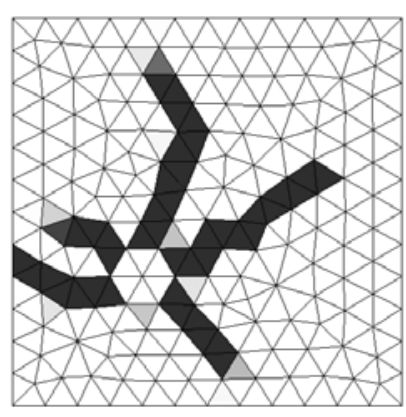

$0.1 \mathrm{E}-3$

$0.2 \mathrm{E}-3$

$0.3 \mathrm{E}-3$

$0.4 \mathrm{E}-3$

$0.5 \mathrm{E}-3$

$0.6 \mathrm{E}-3$

$0.7 \mathrm{E}-3$

$0.8 \mathrm{E}-3$

$0.9 \mathrm{E}-3$

$0.1 \mathrm{E}-2$

weight loss $5.6 \%$

Figure 7. Crack pattern in terms of the maximum tensile strains from numerical analyses with the original and the extended corrosion models with a corrosion rate of $100 \mu \mathrm{A} / \mathrm{cm} 2$.

\section{Comparison with tests}

The model was also used in analyses of eccentric pull-out tests. A brief description of the tests is given here; further details are available in a test report (Zandi Hanjari and Coronelli 2010) and two articles (Coronelli et al. 2010 and Zandi Hanjari et al. 2010). This is followed by a description of the modeling technique and presentation and discussion of the results.

\subsection{Eccentric pull-out tests}

A research program was set up that comprised both the study of corrosion cracking and of bond strength deterioration throughout mechanical testing. In the first phase, the specimens were subjected to accelerated corrosion attack. In the second phase, the external pull-out force was gradually imposed on the tested bar according to the prescribed displacement. The aim was to better understand the effects of high corrosion attacks and of corroding stirrups on cracking and bond strength in anchorage regions. The eccentric pull-out specimens had the shape of a beam-end after inclined shear cracking, see Figure 8. 


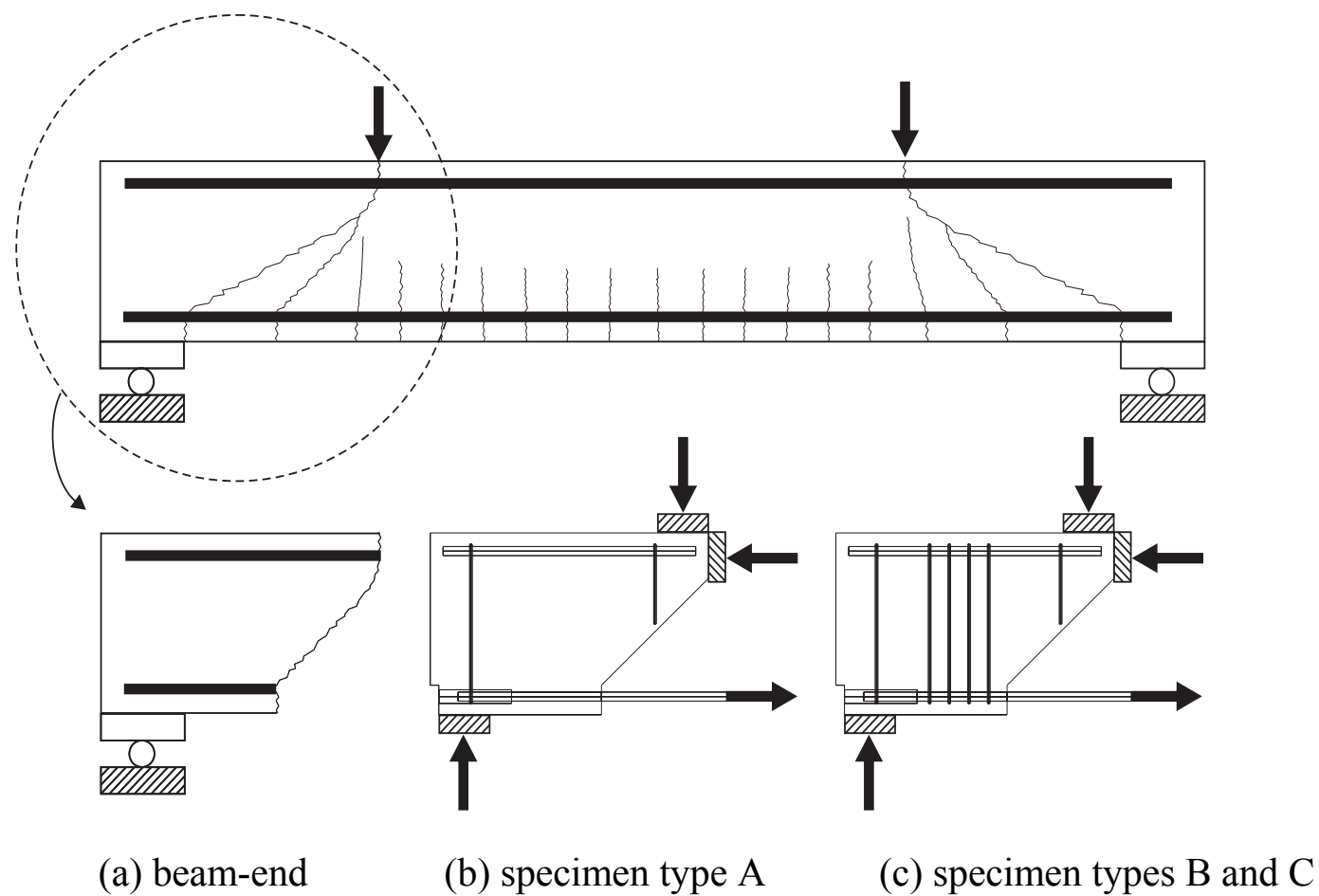

Figure 8. Schematic illustration of: (a) beam-end region, (b) specimen type A and (c) specimen types $B$ and $C$.

The influences of the location of the anchored bar, middle and corner placements; the presence or absence of transverse reinforcement; the corrosion attack of longitudinal reinforcement and of transverse reinforcement were studied. The specimens were of three different types in relation to the reinforcement arrangement and corrosion: specimens without stirrups, where the main bars were corroded (type A); specimens with stirrups where the main bars were corroded and the stirrups were protected by insulating tape (type B); and specimens with stirrups where the main bars and stirrups were corroded (type C). The specimens were subjected to accelerated corrosion, with an average impressed current density of $100 \mu \mathrm{A} / \mathrm{cm}^{2}$. The current flowed through the main bars across the concrete cover to a cathode placed at the top of the specimen, inside a tank containing a solution of $3 \%$ chlorides. This has led the corrosion to attack from one side; therefore, it affected the whole surface on one side of the bar, with some pits. It should be noted that the corroding bars, and consequently the corrosion products, were constantly exposed to a wet environment, meaning that the flow of corrosion products through cracks was facilitated. The specimens were corroded for three time spans that caused a rebar weight loss of up to approximately $20 \%$ in the main bars and $35 \%$ in the stirrups.

All the specimens showed longitudinal cracks along the main bars for a relatively low corrosion attack. The corrosion attack at first cracking was about $0.6 \%-1.0 \%$ rebar weight loss; the cracks widened with increased corrosion attacks.

\subsection{Numerical analysis}

The eccentric pull-out tests were analyzed in detail using non-linear three-dimensional finite element (FE) models by use of the FE program DIANA. The analyses were carried out in two phases. In the first phase, the corrosion attack was applied in time steps as the expansion of the corrosion products. In the second phase, the external 
pull-out force was gradually imposed on the tested bar according to the prescribed displacement. An incremental static analysis was made using a Newton-Raphson iterative scheme to solve the non-linear equilibrium equations.

Due to symmetry, half of the specimen was modeled with an approximate element size of $10 \mathrm{~mm}$, Figure 9. Four-node, three-sided isoparametric solid pyramid shaped elements were used for the concrete, transverse and longitudinal reinforcements. For concrete, a constitutive model based on non-linear fracture mechanics using a smeared rotating crack model based on total strain was applied (DIANA 2009). The crack band width was assumed to be equal to the element size; this was later verified to be a good approximation of the localization zone in the analyses. For the concrete in compression and tension, the models by Thorenfeldt et al. (1987) and Hordijk (1991), respectively, were adopted. The reinforcing steel was modeled according to an isotropic plastic model with the Von Mises yield criterion. The material properties for the concrete and reinforcing steel as well as the input data for the bond model, the original corrosion model and the extended corrosion model, were the same as explained in the analyses of a small portion of the eccentric pull-out specimens; see Section 3.5.

As in the experiments, the longitudinal bars were subjected to corrosion attack from one direction, i.e. half of the main bar cross section was affected by corrosion, see Figure 10. The corrosion attack imposed on half of the main bar cross section was equivalent to the total bar weight loss measured along the embedment length. The bottom leg of the stirrups was subjected to corrosion all around the cross section. The vertical leg of the stirrups was corroded halfway up to the longitudinal bar section. These choices corresponded to the experimental observations. In the experiment, the corrosion penetration depth differed between different bars. In the analyses with the original corrosion model, however, the same corrosion penetration depth was imposed on all of the main bars; this corrosion attack corresponds to the corrosion penetration depth of the bars tested shortly before the pull-out test. In the analyses with the extended corrosion model, the same corrosion attacks as in the experiments were imposed on each bar.

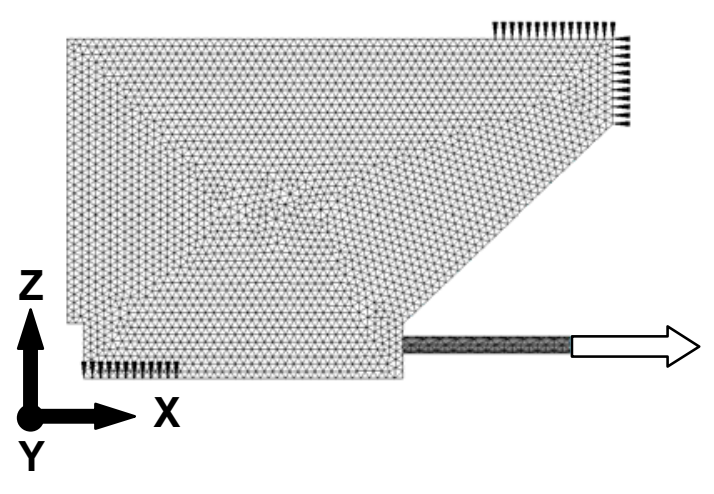

(a)

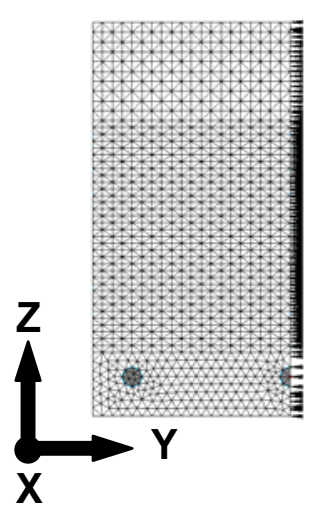

(b)

Figure 9. Finite element mesh with the boundary conditions at (a) the supports and (b) the symmetry plane. 


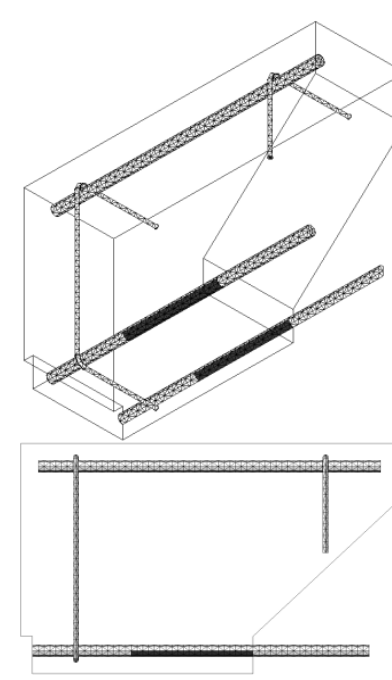

Type A

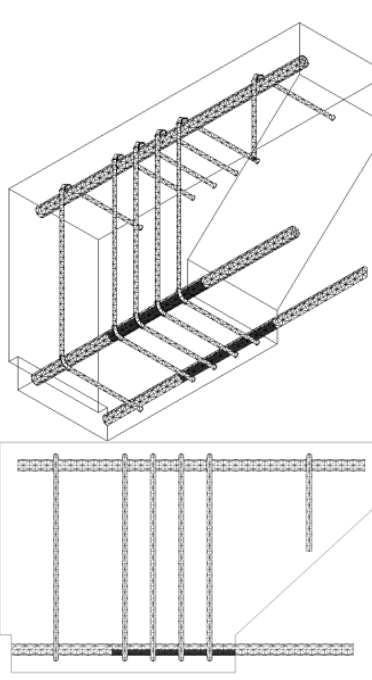

Type B

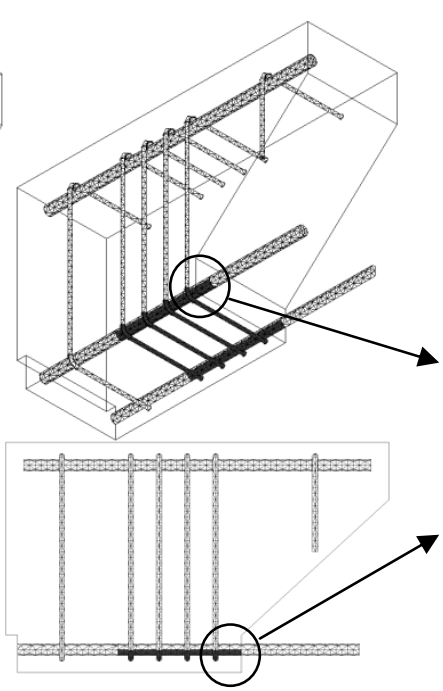

Type C

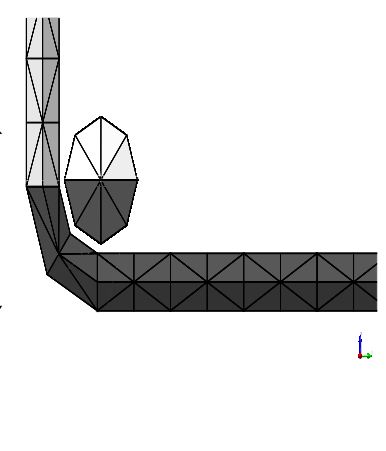

Corrosion

illustration

Figure 10. Finite element model of the eccentric pull-out specimen; the black parts of the bars and stirrups were subjected to corrosion.

\subsection{Results and discussion of corrosion phase}

Corrosion-induced crack pattern in terms of the maximum tensile strains from the numerical analyses with the original and extended corrosion models are compared in Figure 11. The analysis with the original model could only be carried out to a corrosion attack equivalent to rebar weight losses of $1.4 \%, 1.7 \%$ and $0.3 \%$ for specimen types A, B and C, respectively. This corrosion attacks corresponded to extensive cover cracking; for higher corrosion attacks, severe damage of concrete resulted in numerical instability in the analysis. The difference in the corrosion attacks that caused extensive cover cracking and termination of the analyses for the three types of specimens was related to the amount of confinement, i.e. the presence or absence of stirrups and whether or not the stirrups were corroded. However, the analyses with the extended model could be continued with larger corrosion penetration depths. This is an important advantage when the extended corrosion model is used. In general, the crack pattern changed slightly when the effect of corrosion products flowing through the cracks was included, i.e. more cracks were seen in the analyses with the extended corrosion model. This corresponds better to the measurements in the specimens. 
Type A

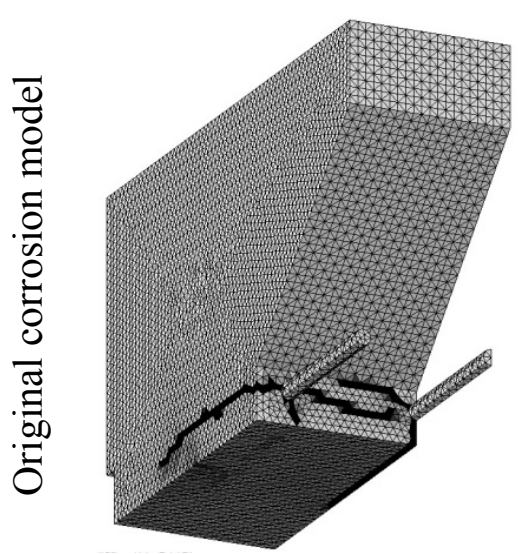

$1.4 \%$ corrosion (no stirrups)

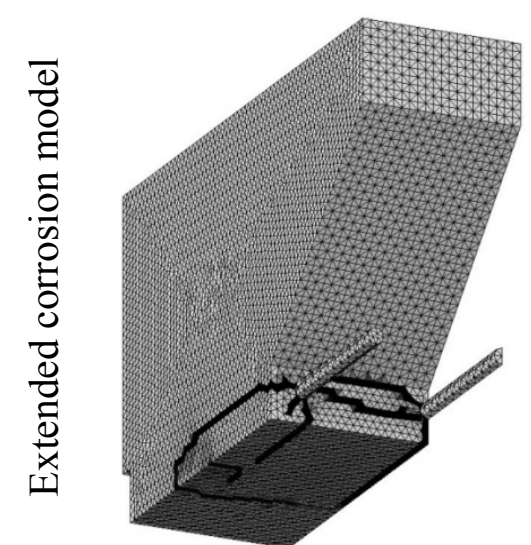

$8.7 \%$ corrosion corner bar $7.9 \%$ corrosion middle bar (no stirrups)
Type B

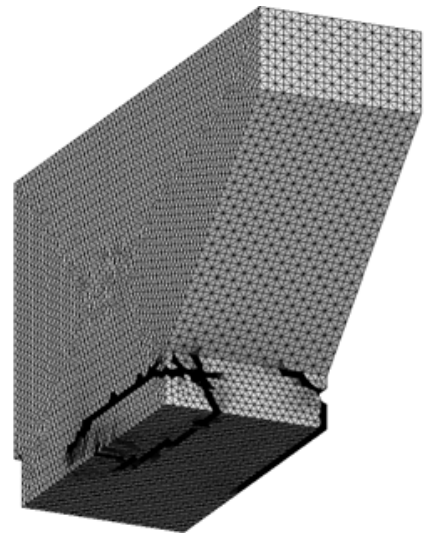

$1.7 \%$ corrosion (main bars only)

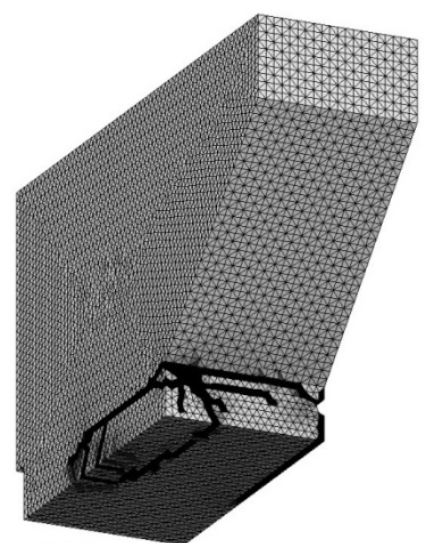

$15.7 \%$ corrosion corner bar $14.0 \%$ corrosion middle bar (main bars only)
Type C

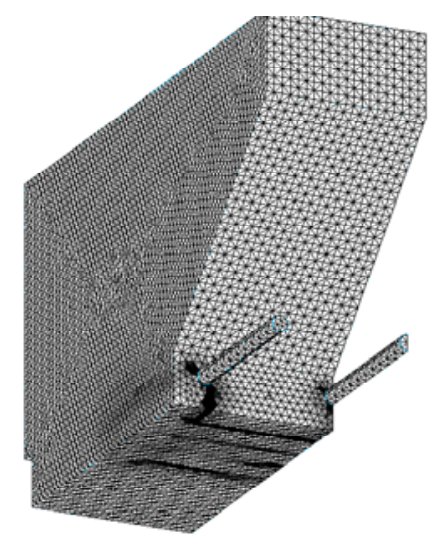

$0.3 \%$ corrosion weight loss (main bars and stirrups)

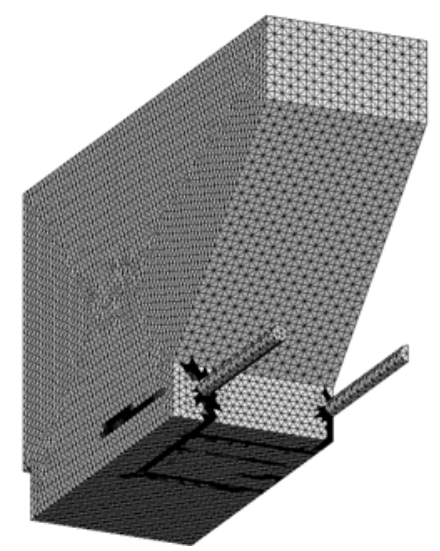

$15.5 \%$ corrosion corner bar

$7.0 \%$ corrosion middle bar

$17.0 \%$ corrosion all the stirrups
$0.1 \mathrm{E}-3$

$0.2 \mathrm{E}-3$

$0.3 \mathrm{E}-3$

$0.4 \mathrm{E}-3$

$0.5 \mathrm{E}-3$

$0.6 \mathrm{E}-3$

$0.7 \mathrm{E}-3$

$0.8 \mathrm{E}-3$

$0.9 \mathrm{E}-3$

$0.1 \mathrm{E}-2$

$0.1 \mathrm{E}-3$

$0.2 \mathrm{E}-3$

$0.3 \mathrm{E}-3$

$0.4 \mathrm{E}-3$

$0.5 \mathrm{E}-3$

$0.6 \mathrm{E}-3$

$0.7 \mathrm{E}-3$

$0.8 \mathrm{E}-3$

$0.9 \mathrm{E}-3$

$0.1 \mathrm{E}-2$

Figure 11. Corrosion-induced crack patterns in terms of the maximum tensile strains from numerical analyses of the eccentric pull-out specimens. The weight loss of the reinforcement is indicated below each figure.

Three main cover cracking patterns were observed in the numerical analysis. In the absence of stirrups, specimen type A, the corrosion-induced cracks around the corner bars propagated in a direction with the least resistance. For this reason, a corner cover spalling took place. In specimen type B, the corrosion-induced cracks, initiated from the corner and middle bars, propagated across the cross-section and formed a delamination plane. A different pattern was obtained when both longitudinal and transverse bars were corroded, specimens type C. In this situation, wide cracks appeared transversely to the main bars, due to corroding stirrups, before any of the former patterns occurred. Thus a more local cover crack pattern, mainly damage of the concrete between the stirrups, formed. As the concrete cover was smaller over the stirrups, the splitting cracks appeared for a relatively low corrosion attack. All the three types of crack patterns agreed well with the experimental observation.

The crack widths measured in the experiments and computed in the analyses with the original and the extended corrosion models for the three specimen types are presented in Figure 12. The analytical crack widths as a function of corrosion attack 
proposed by Molina et al. (1993) and Berra et al. (2003) are given for comparison in the same figure. The model by Berra et al. (2003) is an extension of the model proposed by Molina et al. (1993) to account for the effect of the flow of corrosion products through cracks. The models have been formulated as

$$
\begin{array}{ll}
w_{c r}=2 \pi\left(v_{r s}-1\right) \cdot x & \text { (Molina et al. 1993) } \\
w_{c r}=2 \pi \cdot \frac{r}{r+c}\left(v_{r s}-1\right) \cdot x & \text { (Berra et al. 2003) }
\end{array}
$$

where $r$ is the original bar radius, $c$ is the concrete cover and $x$ is the corrosion penetration depth into the steel bar.

It is of interest to note that the crack widths from the analyses with the original corrosion model agree rather well for low corrosion attacks. When the cracks become wide enough for the corrosion products flow to become important, the original model overestimates the damage and crack widths. The extended model can describe the change in the development of the crack width for high corrosion attacks when crack widths increase at a low rate due to the flow of corrosion products. The crack widths in the extended corrosion model show the best agreement with the experiments for the specimens without stirrups (type A) and the least agreement in the specimens with corroded stirrups (type C). It is seen that, in the type $\mathrm{C}$ specimens, the extended corrosion model underestimates the flow of corrosion products and therefore results in larger crack widths than in the experiments.

The analytical crack widths by Molina et al. (1993) and Berra et al. (2003) both overestimated the crack width; the largest overestimation was seen in the crack width of the specimens with corroded stirrups. Further, neither model reflects the position of the corroded bar, corner or middle, or the amount of confinement, i.e. the presence or absence of stirrups and whether or not the stirrups were corroded.

\subsection{Results and discussion of pull-out phase}

A typical crack pattern and crack widths from the experiment for type $\mathrm{C}$ specimen are shown in Figure 13. The load measured on each bar was divided by the surface area of the bar along the embedment length to calculate the average bond stress. The results are plotted for the analyses with the extended corrosion model and the experiments in Figure 14. The numerical analyses showed good correspondence with the tests results, confirming the failure modes and crack pattern obtained in the tests. The analyses also gave reasonably good results in terms of bond stress versus slip. One small difference between tests and analyses concerns the slip for the uncorroded specimens; the analyses result in weaker behavior with slightly larger slip values for the ascending branch than the test results. This behavior can also be seen in earlier analyses with the bond model used, see e.g. Lundgren, (2005a and 2005b). The main reason for this difference is that the main focus when the bond model was calibrated was the ultimate limit state, with anchorage failure. Thus the bond model needs to be better calibrated for small slip values. 


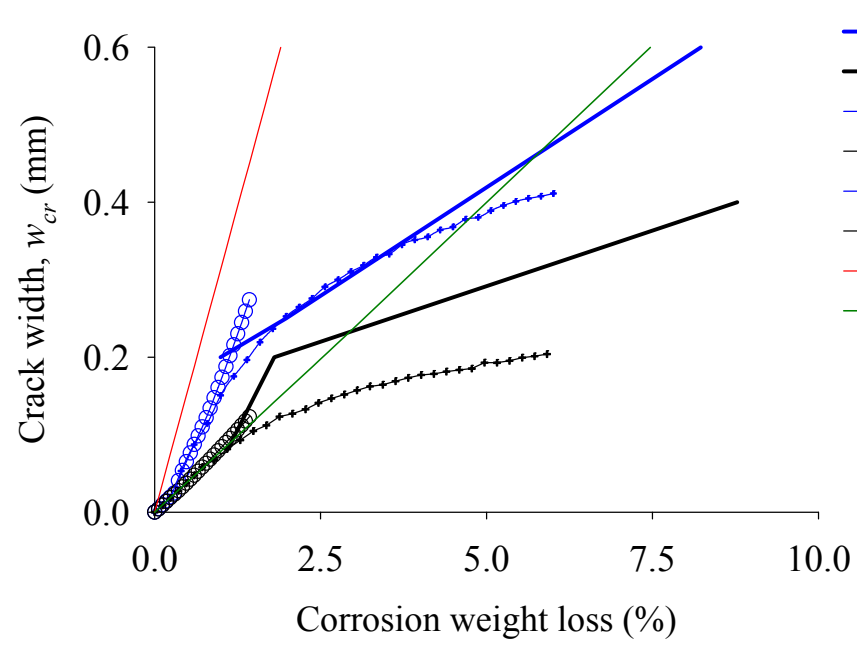

Test: left bar

Test: middle bar

○ Original model: left bar

- $\_$Original model: middle bar

$\longrightarrow$ Extended model: left bar

- Extended model: middle bar

Molina et al., 1993

Berra et al., 2003

(a) specimens type A
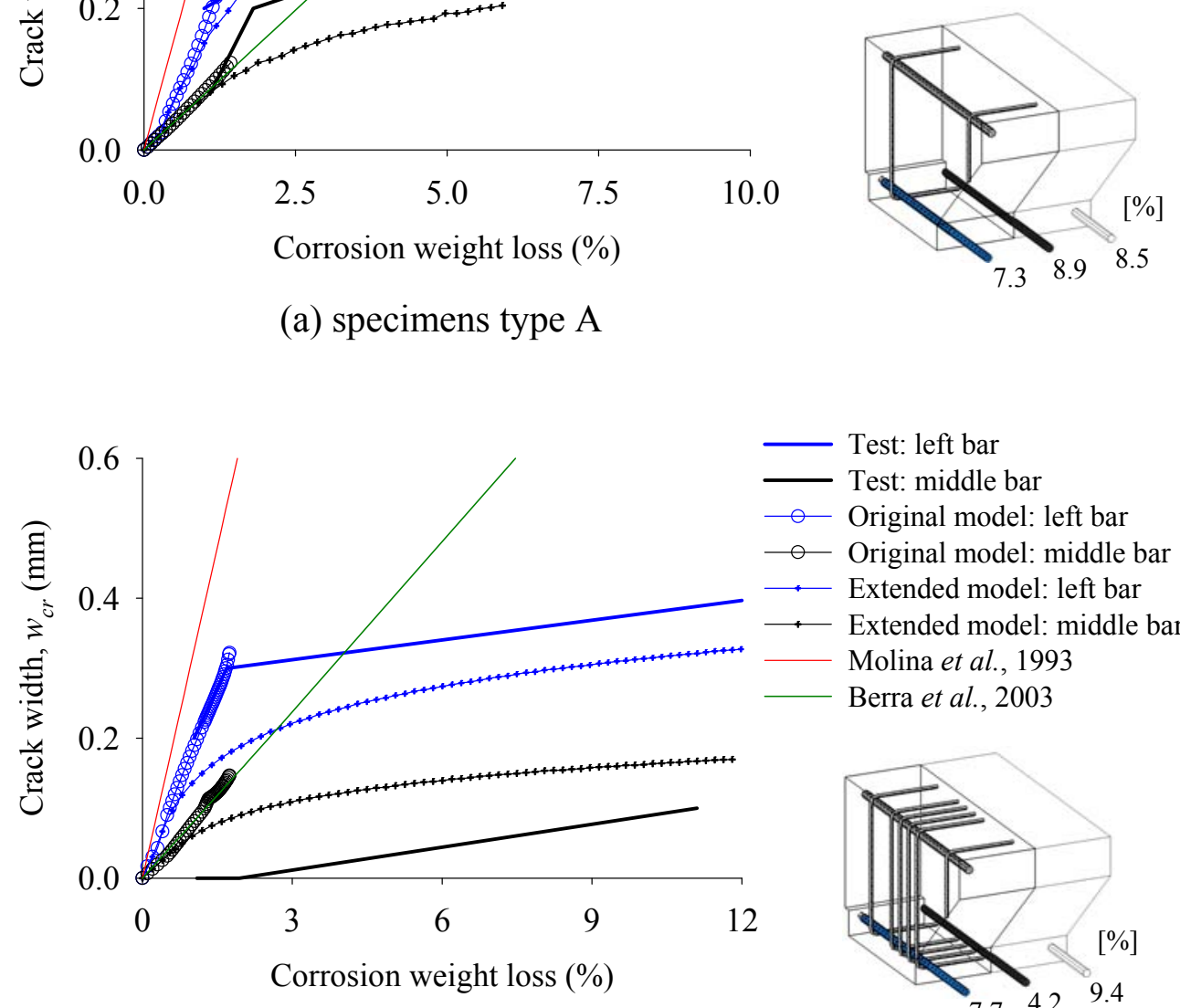

(b) specimens type B

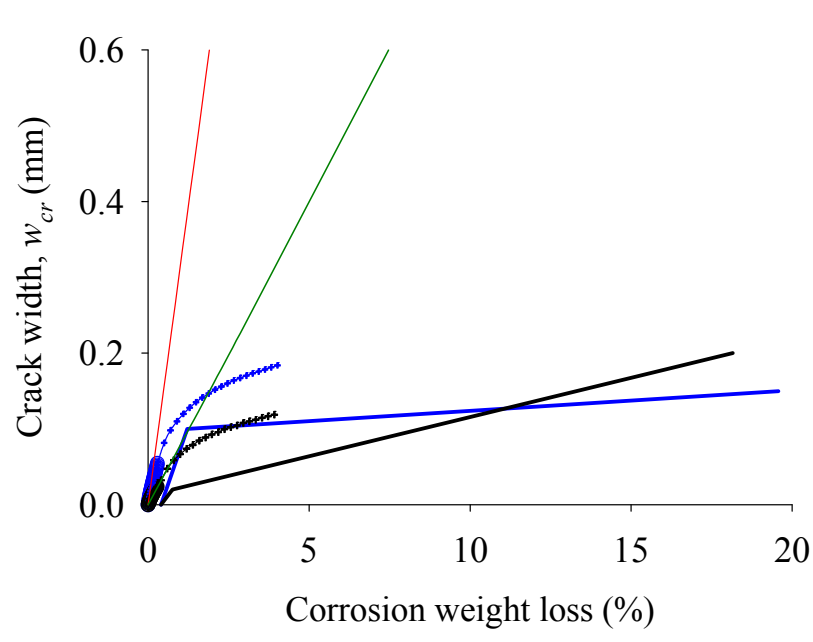

(c) specimens type $\mathrm{C}$

Test: left bar Test: middle bar

- Original model: left bar

- Original model: middle bar

— Extended model: left bar

- Extended model: middle bar - Molina et al., 1993

Berra et al., 2003

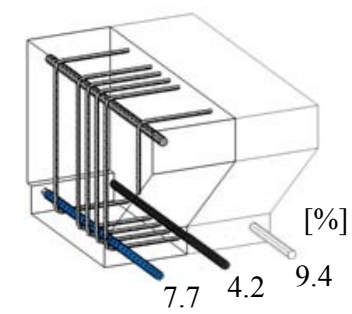

Test: left bar

— Test: middle bar

o Original model: left bar

- Original model: middle bar

$\longrightarrow$ Extended model: left bar

—. Extended model: middle bar Molina et al., 1993

Berra et al., 2003

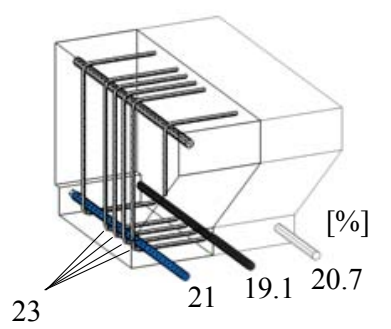

Figure 12. Crack pattern versus corrosion weight loss for specimens of (a) type A, (b) type $B$ and (c) type $C$. 

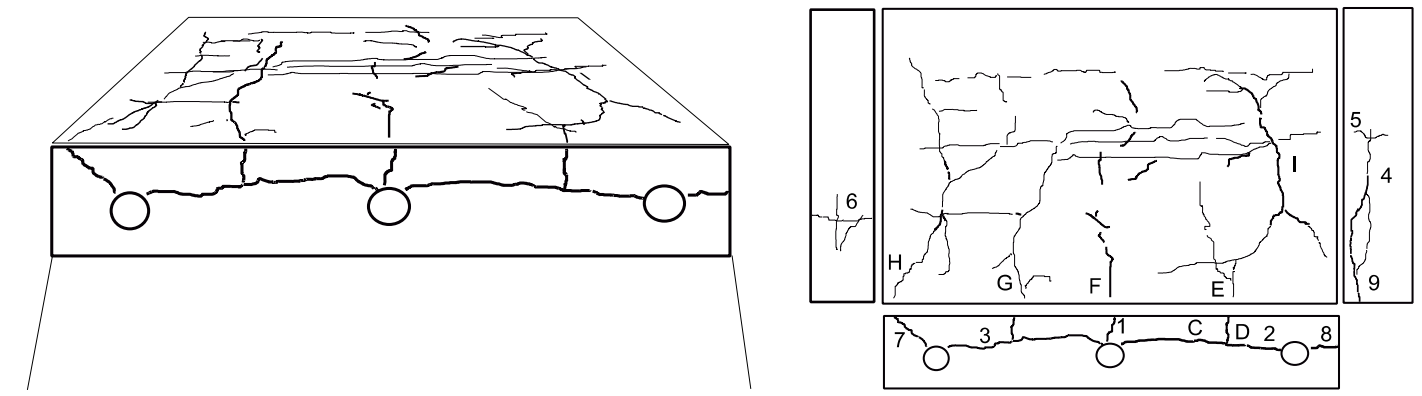

\begin{tabular}{|l|c|c|c|c|c|c|c|c|c|c|c|c|c|c|c|c|}
\hline Crack no. & 1 & 2 & 3 & 4 & 5 & 6 & 7 & 8 & 9 & C & D & E & F & G & H & I \\
\hline Width $(\mathrm{mm})$ & 0.3 & 0.3 & 0.3 & 0.35 & 0.2 & 0.15 & 0.3 & 0.45 & 0.35 & 0.45 & 0.2 & 0.25 & 0.2 & 0.15 & 0.2 & 0.3 \\
\hline
\end{tabular}

Figure 13. Crack pattern and crack widths from the experiments for a type C specimen.

The behavior of the specimens without stirrups, type A, was well predicted, both in the corner bar test and the middle bar test. The agreement was less good when the specimens had stirrups and especially when the stirrups were corroded; the analyses underestimated the capacity. The experimental results showed very little difference between specimen types $\mathrm{B}$ and $\mathrm{C}$ for similar corrosion attacks, while the analysis results indicated a larger effect of corroded stirrups. The experimental observations showed that the concrete cover in both type A and B specimens were extensively cracked due to corrosion, although the crack patterns differed. Type C specimens had cracks that were more distributed and also had several transverse cracks at the position of the stirrups, with a smaller crack width than that in type A specimens, see Figure 13. The difference in the crack width of types A and B specimens is shown in Figure 12 (a) and (b). The crack pattern obtained in the analyses of type $\mathrm{C}$ specimens only showed the large cracks seen in the experiments; the cracks with a small opening did not occur in the analysis. Furthermore, the crack widths obtained in the analyses of type $\mathrm{C}$ specimens were much larger than that measured in the experiments. This might explain the underestimation of the bond capacity in the numerical analysis, as large cracks significantly reduce the confinement and consequently lead to a larger bond deterioration. 


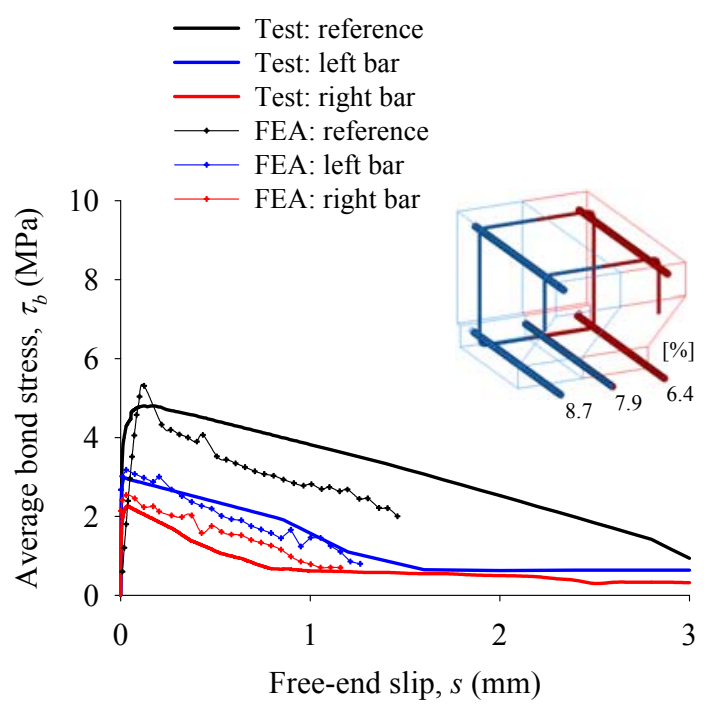

(a) type A - corner bar

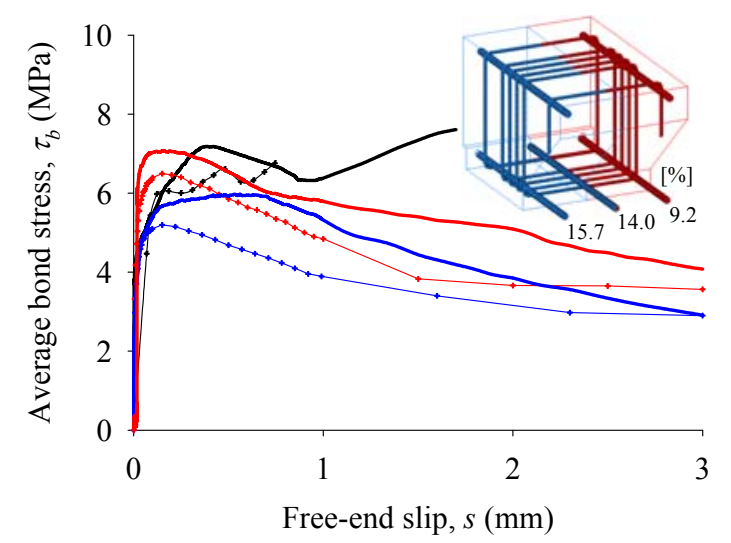

(c) type B - corner bar

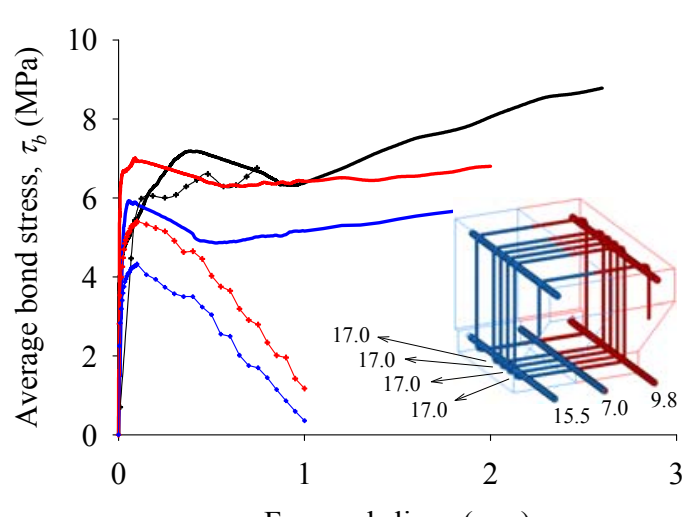

Free-end slip, $s(\mathrm{~mm})$

(e) type C - corner bar

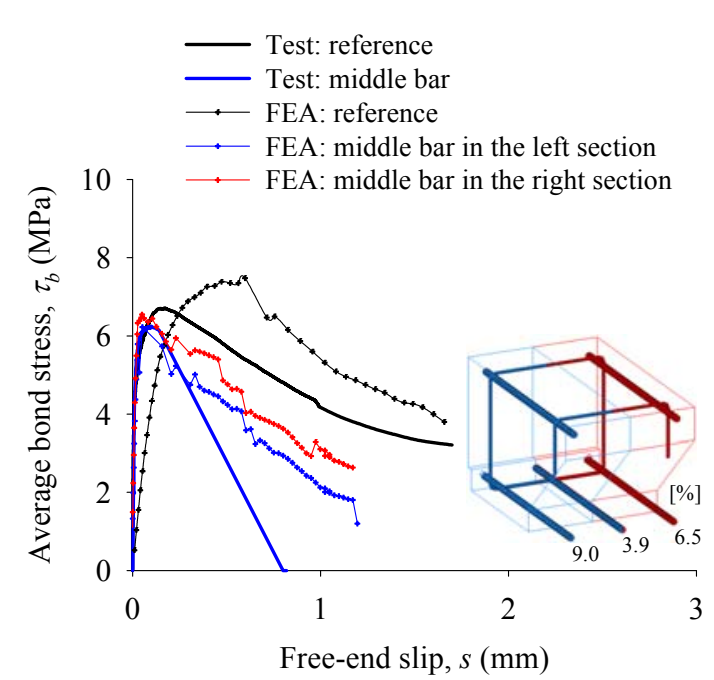

(b) type A - middle bar

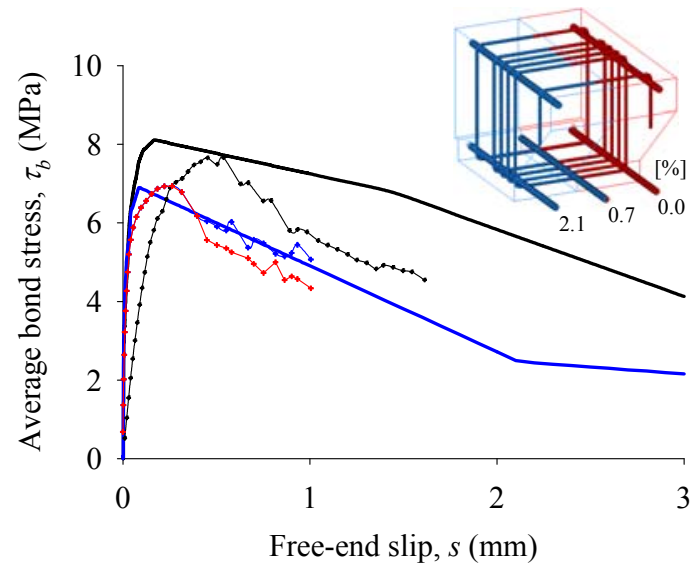

(d) type B - middle bar

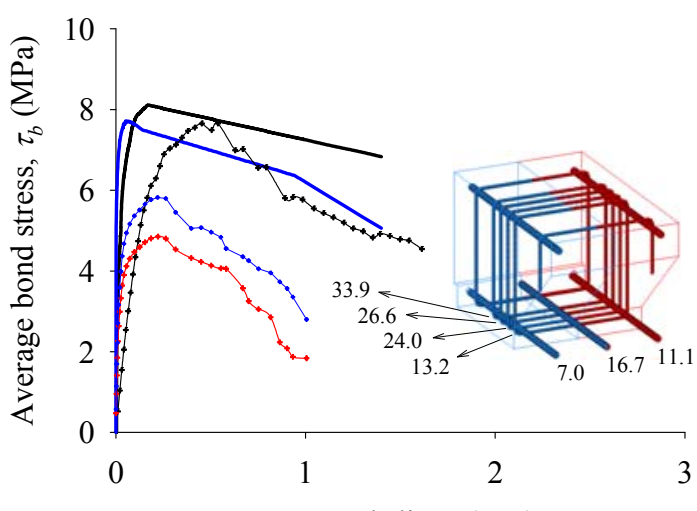

Free-end slip, $s(\mathrm{~mm})$

(f) type C - middle bar

Figure 14. Average bond stress versus free-end slip from numerical analyses and experiments. Pull-out was done for the corrosion level indicated in the small figures. The figure legend given for (a) is valid for (c) and (e), and the figure legend given for (b) is valid for (d) and (f). 


\section{Conclusions}

When high corrosion attacks occur in reinforced concrete structures and wide cracks develop, the effect of corrosion products flowing through cracks becomes significant and leads to a decrease in the splitting stress around the bar. The structure is therefore subjected to less damage. A previously developed corrosion model was extended to include this phenomenon. The original and the extended corrosion models were used in analyses of eccentric pull-out tests and the results, in terms of corrosion-induced crack width and bond capacity, were compared with those measured in the experiments. The following conclusions are drawn on the basis of this study.

(1) A one-dimensional flow model was used to describe the flow of corrosion products through corrosion cracks. It was assumed that the volume flow of corrosion products depends on the splitting stress and the crack width. The results indicated the important effect of the phenomenon on corrosion-induced damage, crack width and bond strength.

(2) The extended corrosion model used in the analyses of eccentric pull-out tests gave results that were consistent with what was observed in the experiments. The extended corrosion model, compared to the original corrosion model, resulted in more corrosion cracks with smaller crack openings.

(3) The crack widths from the extended corrosion model showed the best agreement with the specimens without stirrups and the least agreement with the specimens with corroded stirrups.

(4) A relatively small influence of corrosion products flow was seen shortly after the first cracking. For higher corrosion attacks, when wide cracks propagated, a larger volume of corrosion products flowed through the cracks and led to a significant influence on the crack width. Moreover, the model indicated that the rate of crack width development is directly related to the corrosion rate. But the inverse relation between the corrosion rate and the development of the crack width for corrosion rates lower than $200 \mu \mathrm{A} / \mathrm{cm}^{2}$, which is supported by experimental evidence, is not described by the extended corrosion model and requires further investigation.

(5) Due to the favorable effect of corrosion products flowing through cracks, less damage was observed in the analyses with the extended corrosion model; this corresponds well with the experimental observations. Numerical instability due to extensive cracking of concrete was thus delayed in the analyses that used the extended corrosion model.

(6) In the extended corrosion model, the volume flow of corrosion products also depended on the corrosion rate. A high corrosion rate significantly reduces the corrosion time; a smaller volume of corrosion products thus flows through the crack. Greater differences in the results of the original and the extended corrosion models were seen when a low corrosion rate was adopted.

(7) Several assumptions were made to simplify the formulation of the extended corrosion model. For example, the friction in the crack (for the flow of corrosion products) and the change of the crack width along its depth were not taken into account. Moreover, owing to a lack of information concerning the 
physical state of the corrosion products, the density of corrosion products was assumed to be constant. These assumptions must be studied further.

(8) The effect of the corrosion rate was included in the extended corrosion model using Faraday's law. The model was thus not calibrated with test specimens subjected to different corrosion rates. This is a subject of future research. 


\section{Notation}

\begin{tabular}{|c|c|}
\hline$a$ & Acceleration \\
\hline$c$ & Stress in the inclined compressive struts; or concrete cover \\
\hline$d_{1}-d_{4}$ & Nodal displacements \\
\hline e & Element size along the crack \\
\hline$f_{t}$ & Tensile strength of concrete \\
\hline$i$ & Time step \\
\hline$m$ & Mass \\
\hline$p$ & Exponent describing the granular behavior of corrosion products \\
\hline$r$ & Reinforcement bar radius \\
\hline$t$ & Corrosion time \\
\hline$u$ & Relative displacements across the interface \\
\hline$u_{n}$ & Relative normal displacement at the interface \\
\hline$u_{\text {nbond }}$ & Normal deformation in the bond layer \\
\hline$u_{\text {ncor }}$ & Normal deformation in the corrosion layer \\
\hline$u_{r}$ & Relative displacements in the direction around the bar \\
\hline$u_{t}$ & Slip \\
\hline$u_{\text {tcor }}$ & Slip in the corrosion layer \\
\hline$v$ & Velocity \\
\hline $\bar{v}$ & Mean velocity \\
\hline$w_{c r}$ & Crack width \\
\hline$x$ & $\begin{array}{l}\text { Corrosion penetration depth into the steel bar; or position of a corrosion } \\
\text { products particle }\end{array}$ \\
\hline$y$ & Free increase of the bar radius in the original corrosion model \\
\hline$y_{\text {ext }}$ & Free increase of the bar radius in the extended corrosion model \\
\hline$A$ & Area of element \\
\hline$A_{c r}$ & Section area of crack \\
\hline$D_{11}, D_{2}$ & $D_{33}$ Stiffness in the elastic stiffness matrix \\
\hline$E_{c}$ & Elastic modulus of concrete \\
\hline$F$ & External force \\
\hline$F_{1}$ & Yield line describing friction \\
\hline$F_{2}$ & Yield line describing the upper limit at a pull-out failure \\
\hline I & Impressed current density \\
\hline$K_{c o r}$ & Stiffness of corrosion products in the radial direction \\
\hline$V$ & Volume flow of corrosion products \\
\hline$V_{c}$ & Volume inside the crack \\
\hline$V_{\text {rust }}$ & Volume of corrosion products \\
\hline$\varepsilon$ & Strain in the concrete element \\
\hline$\varepsilon_{c o r}$ & Total strain in corrosion products \\
\hline$\mu$ & Coefficient of friction \\
\hline$\rho$ & Density of corrosion products \\
\hline$\sigma$ & Stress \\
\hline$\sigma_{n}$ & Normal splitting stress \\
\hline
\end{tabular}


$\sigma_{r} \quad$ Stress in the direction around the bar

$\sigma_{t} \quad$ Bond stress

$v_{r s} \quad$ Volume corrosion products/volume steel

$\Delta t \quad$ Time span

$\Delta m \quad$ Change in the mass

$\Delta v \quad$ Change in the velocity

$\Delta V \quad$ Volume flow of corrosion products in a time step 


\section{References}

Alonso, C., Andrade, C., Rodriguez, J. \& Diez, J. M., 1998. Factors controlling cracking of concrete affected by reinforcement corrosion. Materials and Structures/Materiaux et Constructions, 31(211), 435-441.

Berra, M., Castellani, A., Coronelli, D., Zanni, S. \& Zhang, G., 2003. Steel-concrete bond deterioration due to corrosion: Finite-element analysis for different confinement levels. Magazine of Concrete Research, 55 (3), 237-247.

Coronelli, D. \& Gambarova, P., 2004. Structural assessment of corroded reinforced concrete beams: Modeling guidelines. Journal of Structural Engineering, 130 (8), 1214-1224.

Coronelli, D., Zandi Hanjari, K. \& Lundgren, K., 2010. Severely corroded reinforced concrete with cover cracking. submitted to Journal of Structural Engineering$A S C E$.

DIANA, 2009. DIANA Finite Element Analysis, User's Manual, release 9.3. TNO Building and Construction Research, Delft, Netherlands.

EN1992-1-1, 2004. Eurocode 2: Design of Concrete Structures - Part 1: General rules and rules for buildings, CEN European Committee for Standardization, Brussels, $225 \mathrm{pp}$.

Hordijk, D. A., 1991. Local Approach to Fatigue of Concrete. Doctoral thesis, Delft University of Technology, Delft, Netherlands.

Jaffer, S. J. \& Hansson, C. M., 2009. Chloride-induced corrosion products of steel in cracked-concrete subjected to different loading conditions. Cement and Concrete Research, 39 (2), 116-125.

Liu, Y. \& Weyers, R. E., 1998. Modeling the time-to-corrosion cracking in chloride contaminated reinforced concrete structures. ACI Materials Journal, 95(6), $675-681$.

Lundgren, K., 1999. Three-dimensional modelling of bond in reinforced concrete: Theoretical model, experiments and applications. Doctoral thesis, Department of Civil and Environmental Engineering, Chalmers University of Technology.

Lundgren, K., 2002. Modelling the effect of corrosion on bond in reinforced concrete. Magazine of Concrete Research, 54 (3), 165-173.

Lundgren, K., 2003. Modelling the splitting effects of corrosion in reinforced concrete. Computational Modelling of Concrete Structures, Euro-C Conference, St. Johann, Austria: Balkema, 491-500.

Lundgren, K., 2005a. Bond between ribbed bars and concrete. Part 1: Modified model. Magazine of Concrete Research, 57 (7), 371-382.

Lundgren, K., 2005b. Bond between ribbed bars and concrete. Part 2: The effect of corrosion. Magazine of Concrete Research, 57 (7), 383-395.

Lundgren, K. \& Gylltoft, K., 2000. A model for the bond between concrete and reinforcement. Magazine of Concrete Research, 52 (1), 53-63.

Lundgren, K. \& Magnusson, J., 2001. Three-dimensional modelling of anchorage zones in reinforced concrete. ASCE Journal of Engineering Mechanics, 127 (7), 693-699.

Lundgren, K., Roman, A.S.S., Schlune, H., Hanjari, K.Z. \& Kettil, P., 2007. Effects on bond of reinforcement corrosion. International RILEM workshop on Integral Service Life Modeling of Concrete Structures, 5-6 November 2007, Guimaraes, Portugal: RILEM Publications S.A.R.L, 231-238. 
Molina, F.J., Alonso, C. \& Andrade, C., 1993. Cover cracking as a function of rebar corrosion. 2. Numerical model. Materials and Structures, 26 (163), 532-548.

Mullard, J. A. \& Stewart, M. G., 2010. Corrosion-Induced Cover Cracking: New Test Data and Predictive Models. ACI Structural Journal, 108 (1), 71-79.

Ouglova, A., Berthaud, Y., François, M. \& Foct, F., 2006. Mechanical properties of an iron oxide formed by corrosion in reinforced concrete structures. Corrosion Science, 48 (12), 3988-4000.

Richard, B., Ragueneau, F., Cremona, C., Adelaide, L. \& Tailhan, J. L., 2010. A three-dimensional steel/concrete interface model including corrosion effects. Engineering Fracture Mechanics, 77, 951-973.

Saifullah, M. \& Clark, L.A., 1994. Effect of corrosion rate on the bond strength of corroded reinforcement. Proceedings of International Conference: Corrosion and Corrosion Protection of Steel in Concrete, University of Sheffield: Sheffield Academic Press, 591-602.

Shodja, H. M., Kiani, K. \& Hashemian, A., 2010. A model for the evolution of concrete deterioration due to reinforcement corrosion. Mathematical and Computer Modelling, 52, 1403-1422.

Thorenfeldt, E., Tomaszewicz, A. \& Jensen, J.J., 1987. Mechanical properties of high-strength concrete and applications in designed. Conference on Utilization of High-Strength Concrete, Stavanger, Norway.

Yuan, Y., Ji, Y. \& Shah, S.P., 2007. Comparison of two accelerated corrosion techniques for concrete structures. ACI Structural Journal, 104 (3), 344-347.

Val, D. V., Chemin, L. \& Stewart, M. G., 2009. Experimental and numerical investigation of corrosion-induced cover cracking in reinforced concrete structures. ASCE Journal of Structural Engineering, 135 (4), 376-385.

Vu, K., Stewart, M. G. \& Mullard, J., 2005. Corrosion-induced cracking: Experimental data and predictive models. ACI Structural Journal, 102 (5), 719-726.

Wong, H. S., Zhao, Y. X., Karimi, A. R., Buenfeld, N. R. \& Jin, W. L., 2010. On the penetration of corrosion products from reinforcing steel into concrete due to chloride-induced corrosion. Corrosion Science, 52 (7), 2469-2480.

Zandi Hanjari, K., 2008. Load-carrying capacity of damaged concrete structures. Licentiate thesis, Department of Civil and Environmental Engineering, Chalmers University of Technology.

Zandi Hanjari, K. \& Coronelli, D., 2010. Anchorage Capacity of Corroded Reinforcement - Eccentric Pull-out Tests. Report No. 2010-06, Department of Civil and Environmental Engineering, Chalmers University of Technology, Göteborg, Sweden, Dipartimento di Ingegneria Strutturale, Politecnico di Milano, Milan, Italy. Available online at: http://publications.lib.chalmers.se/records/fulltext/140123.pdf [Accessed 16 August 2011].

Zandi Hanjari, K., Coronelli, D. \& Lundgren, K., 2010. Anchorage capacity of severely corroded bars with corroded stirrups. Magazine of Concrete Research [in press]. 